This copy is author's original pre-print version and may slightly differ from the official published version.

Full citation:

Maatta, J., Harkonen, J., Jokinen, T., Mottonen, M., Belt, P., Muhos, M. and Haapasalo, H. (2009) 'Managing testing activities in telecommunications: A case study', Journal of Engineering and Technology Management, Vol. 26, No. 1-2, pp. 73-96.

DOI: 10.1016/j.jengtecman.2009.03.008

\title{
Managing testing activities in telecommunications: A case study
}

\author{
Juha Maatta, Janne Harkonen*, Tauno Jokinen, Matti Mottonen, Pekka Belt, Matti Muhos \& \\ Harri Haapasalo
}

Department of Industrial Engineering \& Management, University of Oulu, Finland

\begin{abstract}
This paper examines ways of managing testing more efficiently and effectively. The importance and the workload of testing have been growing constantly in the telecommunication industry, as a result of shorter product lifecycles and decreased time-tomarket. At the same time, the complexity of products has increased with a decrease in physical dimensions. Managers face enormous challenges in developing knowledge and effective testing processes. This paper proposes the application of two models, a testing optimization model and an extended V2M2 (Verification Validation Maturity Model) model, for managing the value of testing. In the empirical part of the study, the present state of testing management is examined. JEL classification: $\mathrm{O} 32$
\end{abstract}

Keywords: $\quad$ Testing; Management of testing; Maturity model; Lifecycle of testing; Economic test coverage

\footnotetext{
* Corresponding author. Tel.:+358 8553 7805; fax: +358 85532904.

E-mail address: janne.harkonen@oulu.fi
} 


\section{Introduction - The Significance of Testing}

The telecommunication industry is undergoing constant and rapid changes. The competition in the mobile device market has become increasingly fierce between manufacturers; thus sales prices and profit margins are decreasing as a consequence. (Dulaney et al., 2006). One way to gain profit and increase the market share is to launch more, new, high quality and innovative products, earlier than the competitors, which means shortening design lifecycles (Perttula, 2004). The complexity of products (Fig. 1) has increased (1) along with the decrease in physical dimensions (Jokinen, 2006). The workload of testing has been growing constantly in the telecommunication industry, as illustrated in Fig. 2, because of the shorter product lifecycles and decreased time-to-market. "The more complex a system becomes, the more resources are required to test it. But clearly from the perspective of the entire industry, the growing complexity and cost of test can only be considered as painful." (Rumney, 2003).

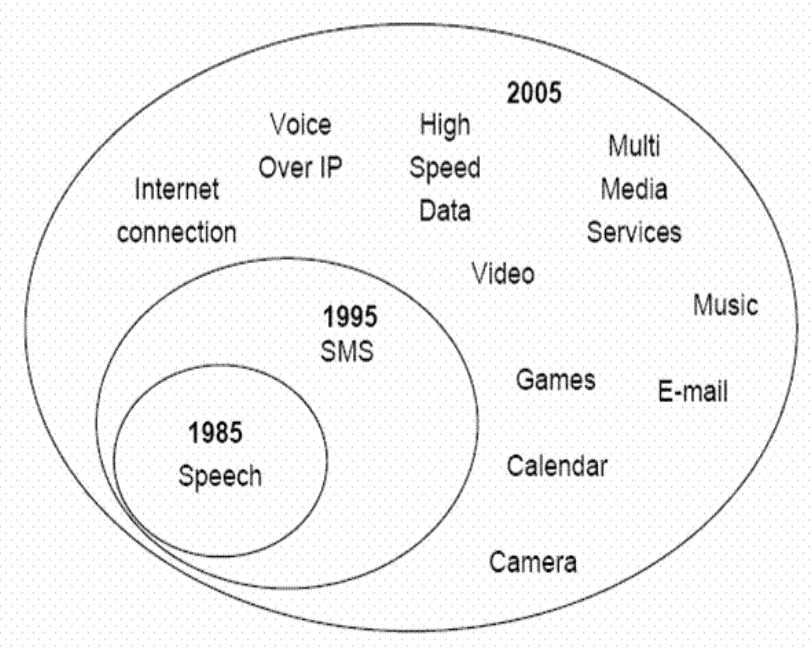

Fig. 1. The increasing complexity of mobile products (Modified from Jokinen, 2006) 


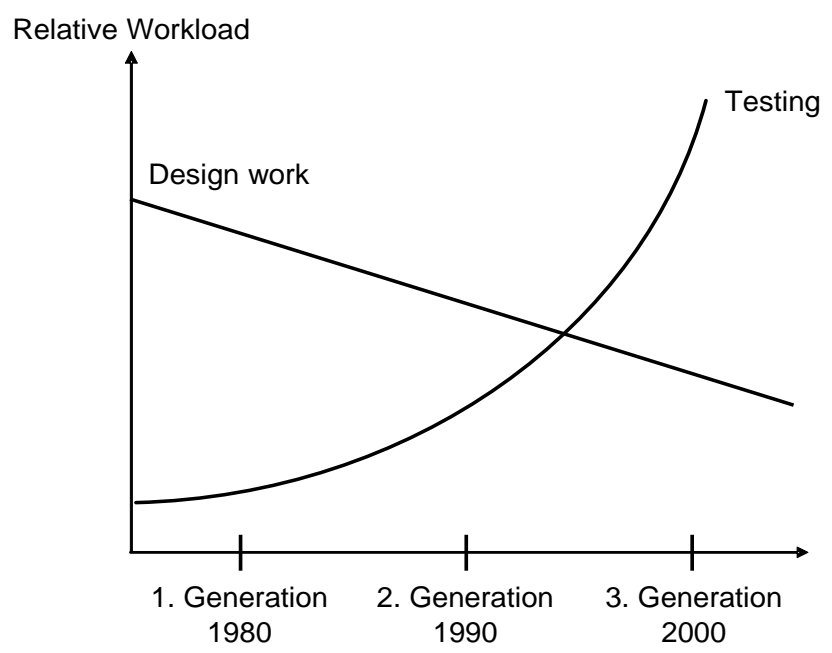

Fig. 2. Relative workload of the telecommunication product development, while the design work has become more effective (Modified from Jokinen, 2006)

Testing activities have been estimated to take between 40 and 80 percent of the entire costs in high-technology telecommunication product development, therefore, testing has become a critical factor for success (e.g. Davis, 1994; Kit, 1995; Harrold, 2000; Kung et al., 1998; Jacobs and Trienekens, 2002; Andersson and Runeson, 2002; Perttula, 2007). The changes in the business environment, with fast time-to-market and demands to decrease R\&D costs have increased the importance of efficient product creation process (Gilb, 2005), including testing (Perttula, 2004). Also, Griffin (1997) has recognized the need to define more explicitly, which industry factors have a significant impact on product development cycle time, even though she does not specifically mention testing as one of these factors. A survey by Andersson and Runeson (2002) shows that in practice; all companies have problems with their testing processes. 
The managers in this field have faced enormous challenges in developing knowledge and processes for testing due to increasingly critical and complicated testing activities. The value of testing has become a remarkable factor within the telecommunication product process.

Designing quality into the product is increasingly more challenging and adding more tests does not make sense financially, although testing still makes sense and pays its way in the long run. "Testing is migrating from a quality-gate role to a value-added role on the path to improving yield outcome" (Jahangiri and Abercrombie, 2005). However, due to financial and schedule restrictions, testing cannot be executed or justified to the current extent. Products should be made and tested to a level that makes the most sense financially in the environment at that time. Kessler (2000) has noted that "smarter" top-management involvement and early testing may be more important than sheer magnitude of involvement and testing. Therefore, testing needs to be optimized and the value added must be made more visible.

Almost every book, dealing with testing, starts with a section that gives reasons for testing. Why is this the case? Simply because testing is often regarded as a necessary evil which takes too much time and money. "As an example, chip manufacturers have always viewed test as a nonvalue-added quality check, and the cost of that quality check has historically remained economically viable. With the explosive growth of chip complexity at the nanometer level, the number of test cycles required to fully test the device has exceeded the cost threshold for most manufacturers" (Jahangiri and Abercrombie, 2005). However, some engineers argue that testing does not add value to a product or process, especially when they are constrained to "looking after the pennies" tightly. Should they be looking to save some money in the short run, there is a strong desire to eliminate testing. The value added by testing is usually difficult to see directly. 
Therefore, the different authors need to justify the existence and importance of testing at the beginning of their books. Nonetheless, the main focus should be in proving explicitly, how value is added by these activities, or how testing can be optimized to maximize this value, and what kind of tools can be used to measure this value.

The way of thinking learned during the quality revolution of the 1980s has contributed to the undervaluation of testing activities. (e.g. Davis, 1994; Black, 2004; Pol and Veenendaal, 1998). During this time, thousands of people received quality training, for the first time, in a wider scope. The message was mostly as follows: "Do everything right the first time, every time, and there will be no need for testing". Davis (1994) admits that the message is quite right. However, this statement talks about quality in general, with regard to all kinds of manufacturing and service industries. At the same time, software and electronics industries are notably different in terms of frequent technology change, increase in complexity, time-to-market pressures and the decrease in physical dimensions in electronics. These factors set enormous challenges for design, manufacturing, maintenance and procurement, which are unmatched by the challenges of any other industry. In the telecommunication industry it is impossible to design and manufacture products without defects (Davis, 1994; Black, 2004; Pol and Veenendaal, 1998, Woodward and Hennell, 2005).

As stated above, testing is required under certain circumstances to mitigate the risks related to quality. Naturally, the ultimate objective is to prevent faults, instead of - as above and often in an expensive way - detecting and fixing the faults at different stages of the product process. Nevertheless, in order to stay competitive, organizations must make quality related investments, including investing in testing, to meet the expectations and requirements set by the customers. 
At this stage, to be able to answer the question, whether testing adds value; we refer to what Davis (1994) has written in his book: "Testing has always been a cost-avoidance activity. We test because it is cheaper to test than not to test". This statement is justified by the fact that the costs incurred in testing are lower than the costs of fixing and repairing the faults in the field. Furthermore, faulty products would eventually lead to the loss of customers, which is difficult to quantify directly as the value of testing. Another noteworthy question is as to, when the total quality costs reach the minimum, i.e. where the sum of testing costs and failure costs are minimized (Black, 2004). Assessing the potential business costs in relation to various risks aims to provide an answer to the question whether and how much testing performance is optimized.

This paper presents the answers to the research questions by discussing the management of testing as part of the innovation cycle, including R\&D, new product development, productization, after-sales, etc. This paper shows some evidence of the inadequate level of attention given to managing testing activities, and describes ways of enhancing the efficiency and effectiveness of testing. Testing is strongly compartmentalized, and is often seen as SW (software), V\&V (verification and validation), HW (hardware) testing, and so forth. Nevertheless, an approach that integrates the whole process is required to manage testing over the value chain. This paper presents a viewpoint on risk based testing and quality costing, showing how they can together provide a positive contribution to the decision-making (Chapter 2). The value-adding nature of testing from the management perspective and the application of maturity models to manage the value of testing are also discussed (Chapter 3 ). The empirical part (Chapter 4) of the paper describes the current status in testing management obtained from 
our case (telecommunication) companies. Finally, some challenge and success factors for testing activities, based on the empirical research, are presented.

The above mentioned aims can be summarized in the following research questions: (RQ 1) What is the current level of managing testing activities at different phases of a value chain?

(RQ2) Do risk based testing and quality costing make positive contributions to optimizing testing?

(RQ 3) How can the maturity models be utilized in managing testing activities?

(RQ 4) What are the challenge and success factors of testing activities in the telecommunications industries?

The scope of the research covers the telecommunications industries and thus may be extended to cover the ICT (Information and Communications Technology) industries. Testing is seen as a broad concept in this study (HW, SW, V\&V, others), aiming not to make any unnecessary exclusions, and attempting to detect the similarities in different types of testing with a special emphasis on the management perspective. The research approach that has been adopted for this study is descriptive, as the paper aims to describe the current phenomena around testing activities. Portraying testing was done from a holistic viewpoint, supported by the research data arising from the empirical research. 


\section{Risk Management and the Optimization Model}

The evident reasons for testing are to detect faults in the deliverables. Faults arise from a variety of sources, partially because there is an economic benefit to pushing processes well beyond the level where they can operate defect-free. Problems faced in managing product quality lead to a variety of risks in business. The value of testing is based on the information obtained by testing and, by managing the risks unfolding in the product development and deployment. Nonetheless, testing activities should concentrate purely on risks. Also, Redmill (2005) states that testing should be focused according to the severity of the identified consequences of such risks. The assumption of all testing being risk-based is not as obvious as one might think at first, (Bach, 1999). Risk based-testing can help to increase the confidence that one is testing the right things at the right time. Therefore, should there be any components in the product that involve no risk, those components should not be tested. There are rarely any situations where all the risks can be thoroughly covered so compromises must be made in testing. Nevertheless, the risks that can lead to financial losses, or much worse, loss of human life, are unacceptable. By figuring out the most critical risks, testing can be optimized accordingly. (Kit, 1995).

Risk is a problem that might happen. Bach (1999) explains the risk as follows: "The magnitude of a risk is a joint function of the likelihood and impact of the problem-the more likely the problem is to happen, and the more impact it will have if it happens, the higher the risk associated with that problem". In fact, testing always deals with potential risks in deliverables, whether it is risk-based or not. A risk-based approach makes the justification of testing efforts more agreeable and understandable, when compared to a situation where the risks are not 
considered. The value of testing is usually extremely difficult to identify and quantify without risk-based assessment.

Testing as a term has no single clear definition that is accepted widely among various disciplines. The focus of testing is not clear enough and the existing definitions do not emphasize the risk approach. Testing as a term has several meanings, depending on the discipline and the subject being tested. Regardless of the broad concept, testing is used in many areas such as materials, components, sub-assemblies, applications, techniques, technologies, methods and processes. Furthermore, testing may be focused on a specific attribute such as functionality, performance, capacity, usability, reliability, security and so forth. The software testing literature has various definitions for testing (e.g. Myers, 1976, Pol and Veenendaal, 1998), whereas the literature on electronics testing has its own definitions (e.g. Burns and Roberts, 2001; Davis, 1994; Landers et al., 1994; Abramovici et al., 1990). Mostly the definitions have right dimension for testing, but they often overlook many vital aspects. We examined a variety of definitions for testing, and due to the absence of an appropriate definition, we define testing, for the purpose of this study, as follows: Testing is a process of performing planned, prepared and controlled activities to evaluate the uncertain quality level of the object and/or processes, assisting to determine the extent to which processes meet the requirements and/or the specifications set prior to testing (Jokinen and Maatta, 2005). This definition identifies the following elements as essential in risk based testing:

- A proactive and systematic approach

- Feedback

- $\quad$ Predefined requirements for testing

- Can deal with particular uncertainties. 


\subsection{Quality Costing and the Optimization Model}

Quality costing offers a tool for assessing and measuring the accurate value of testing related to the quality risks involved in product development. For example, Yasin et al. (1999) have pointed out the managers' dilemma, involving concerns related to problems regarding when and how much to spend on quality improvement initiatives as they search for the optimal quality level, and actually found the cost of quality (COQ) models (e.g. Feigenbaum, 1961) helpful. No matter which quality costing approach is used, the main idea behind the analysis is the linking of improvement activities with associated costs and customer expectations (Schiffauerova and Thomson, 2006). Also the financial and schedule risks are dependent on the quality of the products and processes, thus quality costing serves only as an overall measuring tool for the value of testing. This, in turn, allows a calculation of the return on investment for testing activities. Therefore, quality costing provides a tool for optimizing testing as an independent factor, in the same way as any other independent business function.

Traditionally, quality costs have been divided according to Feigenbaum's Prevention, Appraisal, and Failure (PAF) model (Feigenbaum, 1961) into three separate categories, as follows:

1. Prevention costs (costs of doing it right the first time)

2. Appraisal costs (costs of checking it is right)

3. Failure costs (costs of getting it wrong).

Failure costs have been typically divided further into internal and external failure costs. The PAF model has been criticized because of an impractical classification of quality costs, as many 
times one specific quality cost can be understood as any of the following: prevention, appraisal, or failure cost. Technically this does not get support from cost accounting systems (Moen, 1998; Oakland 2000; Porter and Rayner, 1992). The PAF model presumes that there is a certain point of optimal quality level, above which there is a trade-off between investments in prevention and failure costs. Sometimes this is criticized for not encouraging continuous improvement. (Sippola, 2000; Feigenbaum, 1961). It has been shown theoretically that, within an infinite timeframe, prevention costs are always financially justified (Swinkels, 2000). However, in practice, the resources of any given company are limited and the prevention activities should focus on the most beneficial areas of the improvement efforts.

Another essential challenge when calculating failure costs is in relation to speculative costs, such as customer dissatisfaction. The Poor Quality Cost (PQC) model of Moen (1998) is an extension of the quality costing models, as it also pays attention to both direct and indirect failure costs. Direct costs are known and can be monitored by an internal cost accounting system. Indirect costs are the speculative costs first perceived by the customer, and subsequently returned to the company as lost market shares. The basis for both categories is customer requirements, needs and expectations. (Moen, 1998). The PQC model enables us to obtain a more accurate view over the cost of poor quality. With the support of the PQC model, testing can be optimized assuming that the costs of testing are known.

Attempts have been made to estimate the optimal release decision point, i.e. the point where the cost of finding more defects exceeds the costs incurred by the defects remaining, as illustrated in Fig. 3 (Brown and Kane, 1984). This paper introduces a novel approach to this by taking advantage of accurate failure costs. A new optimization model illustrated in Fig. 4 is presented 
in this study. The purpose of this new model is to compare testing costs with failure costs obtained by the PQC model in terms of Economic Test Coverage (ETC). "Economic test coverage is a measure of the economic coverage of the most significant risks faced in product processes". (Jokinen and Maatta, 2005). This, in turn, enables us to optimize testing totally on an economical basis by providing maximal financial value for testing as depicted in Fig. 4. The purpose of these illustrations is merely to introduce a change in the mindset for the value of testing.

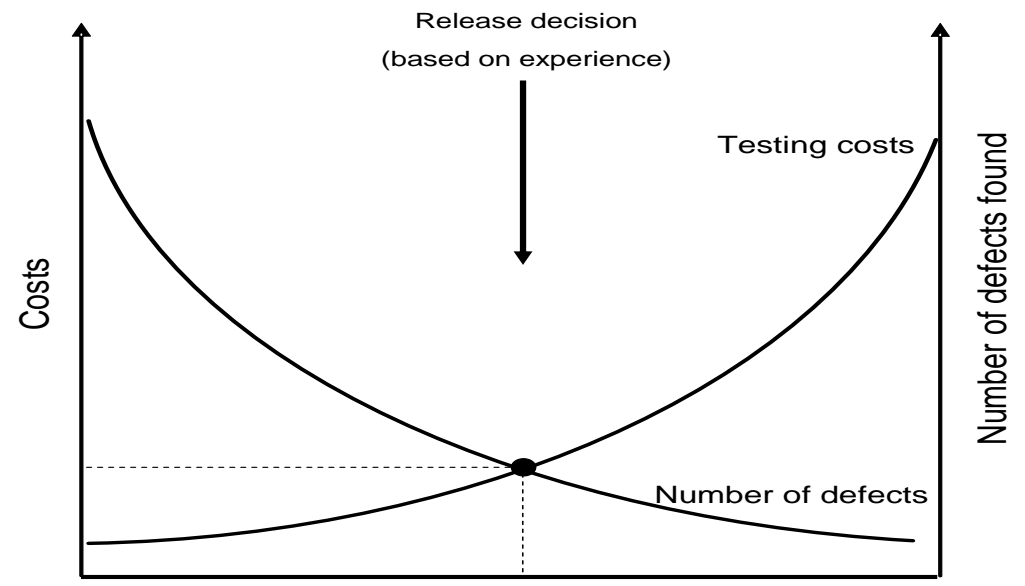

Time spent in development \& testing

Fig. 3. A way of estimating the optimal release decision point (Brown and Kane, 1984). 


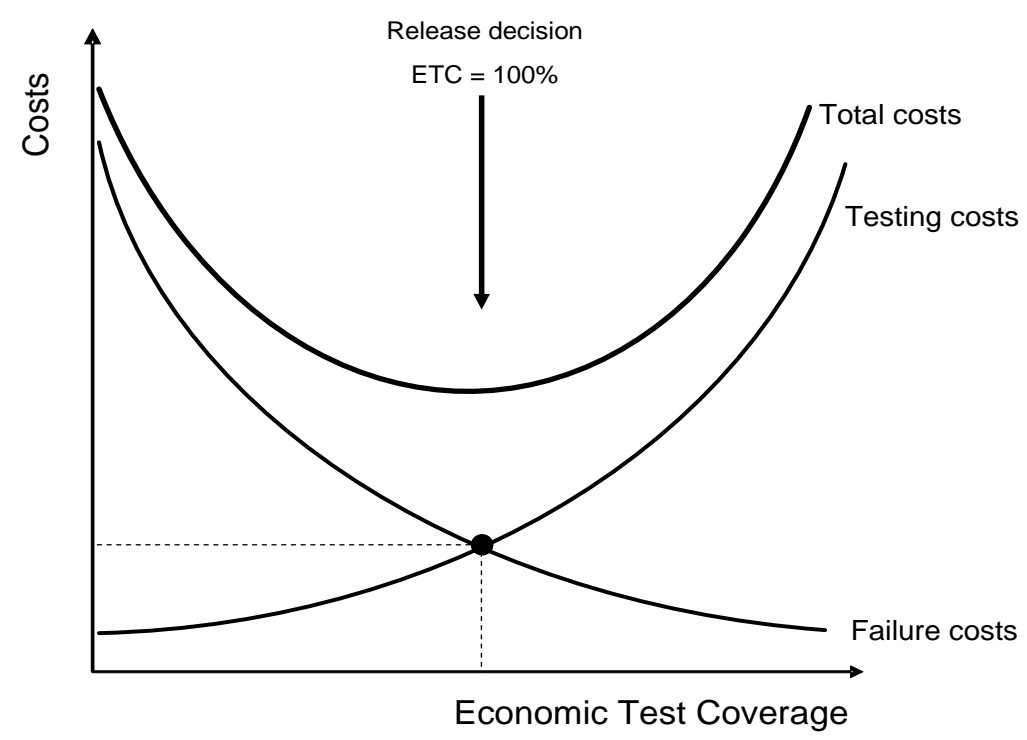

Fig. 4. A new optimization model based on quality costing and risk analysis, enabling optimization of testing on an economic basis.

This new model can be challenged by the fact that failure costs are not known in advance; rather it takes years to gather data about these costs. However, the failure costs are obtained by using the PQC model from the historical data and empirical evidence accumulated in past projects. Mature organizations have had robust databases and data monitoring systems in use for years providing accurate information about the costs of failures and testing. Organizations without the required historical data available have to rely on estimates in the beginning, due to the absence of accurate data. Mottonen et al. (2006) have studied the optimization model with empirical data and found it applicable to the telecommunications industry.

\subsection{Quality Costing and Testing Maturity}

The maturity of the overall test process is a crucial factor in terms of the financial value of testing. The term 'maturity' is used here for the maturity of the level of operations, as in the 
existing models or frameworks (for example, Ahern et al. 2004, Bate et al. 1995, Burnstein 1996, Chrissis et al. 2003, Krause 1994). To increase their maturity, organizations need these frameworks or models as a guideline for improvements. Maturity models of testing aimed to enhance maturity will be discussed in section 3.2 below. In addition, Fig. 5 depicts the impacts of testing maturity in the context of failure and testing costs.

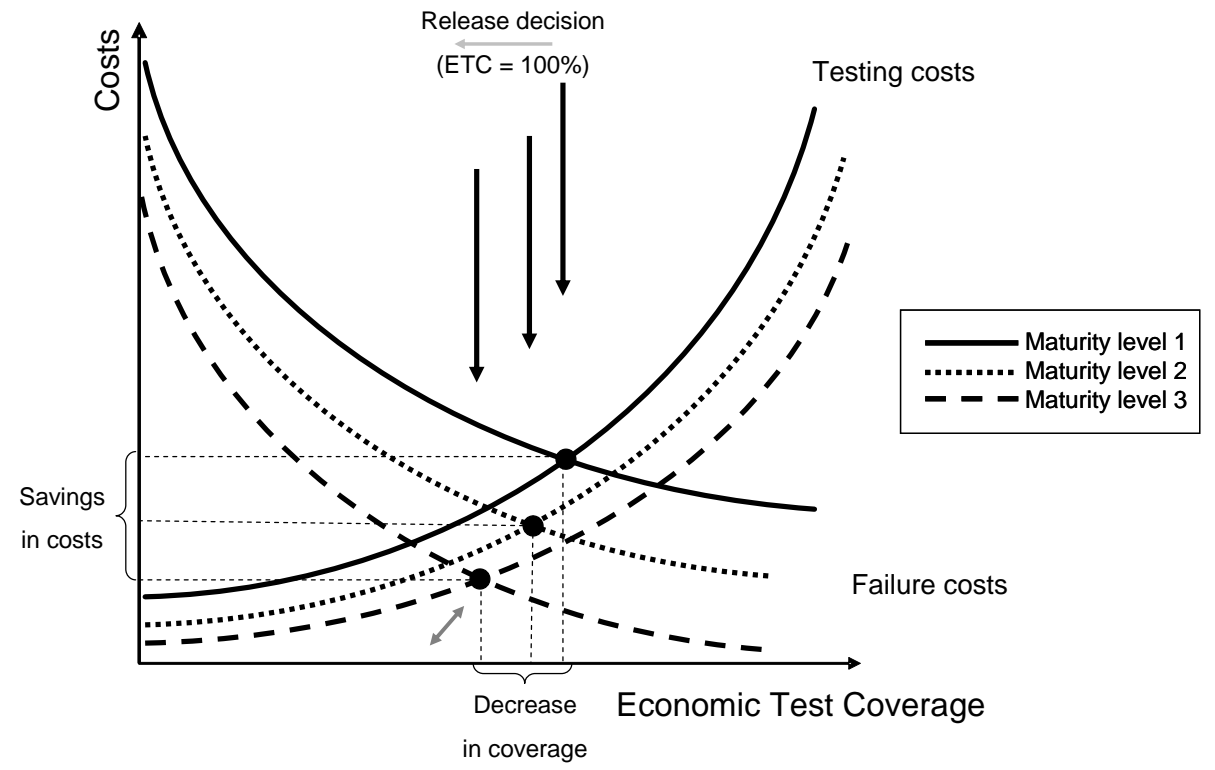

Fig. 5. Theoretical impact of testing maturity on the costs of failures and testing.

Our initial, educated hypothesis is that optimum total costs and test coverage decrease while maturity increases. These can be explained by the following facts:

1. as testing maturity increases, the equal test coverage can be obtained with fewer costs;

2. failure costs are dependable on testing maturity, due to the more mature test process recognizing defects earlier, hence yielding lower failure costs;

3. test process maturity and overall organizational maturity are closely interrelated. High test process maturity cannot be achieved within an immature organization. Consequently, high organizational maturity contributes to the test maturity, high quality, and lower failure costs. 
These facts together have an influence on the total costs within each maturity level. The PQC model (Moen, 1998) is recommended in this approach, to determine the optimal release point, which can be achieved by lower total costs and test coverage as the maturity increases. In addition, optimal test coverage allows the avoidance of excessive costs incurred by unnecessary testing, as the cost curves illustrate in Fig. 5. This approach also strengthens our view of lower failure costs within high quality processes.

Quality costing combined with a risk-based approach would permit streamlining of the testing efforts. Quality costing involves value based evaluation, whereas the risk-based approach involves an assessment of the occurrence, severity and the probability of elements associated with testing related issues. These factors together provide an adequate information base for decision-making. These factors could also be used to calculate Economic Test Coverage (ETC), which would act as a tangible metric or measure for managing testing activities. ETC, or an equivalent as a measure, is currently not being used, nevertheless it would be useful for estimating whether a sufficient amount of risks have been covered by testing activities, and to indicate when no further testing is required. Testing would be at an optimum when the ETC value is $100 \%$. The object would be over or under-tested when the obtained ETC value is higher or lower than $100 \%$ respectively. One should note that the firm is losing money, or the probability of losing money is significant, should ETC not be at an optimum. As an example, under-testing can cause an indirect loss of market share, or even worse, the loss of human life, yet over-testing does not bring any cost benefits and may adversely affect the timely release to the markets. It should be noted that "economic test coverage" is a different term than "test coverage". The latter is often used in testing literature to indicate the completed tests in the entire test universe. Therefore, we propose the optimization of testing via the utilization of ETC 
metrics, clarified in Fig. 6 which is based on multiple assessments instead of purely making a decision on the value basis. The added value enhances, accordingly, whilst the non-value adding elements can be discounted de facto as described in Fig. 6.

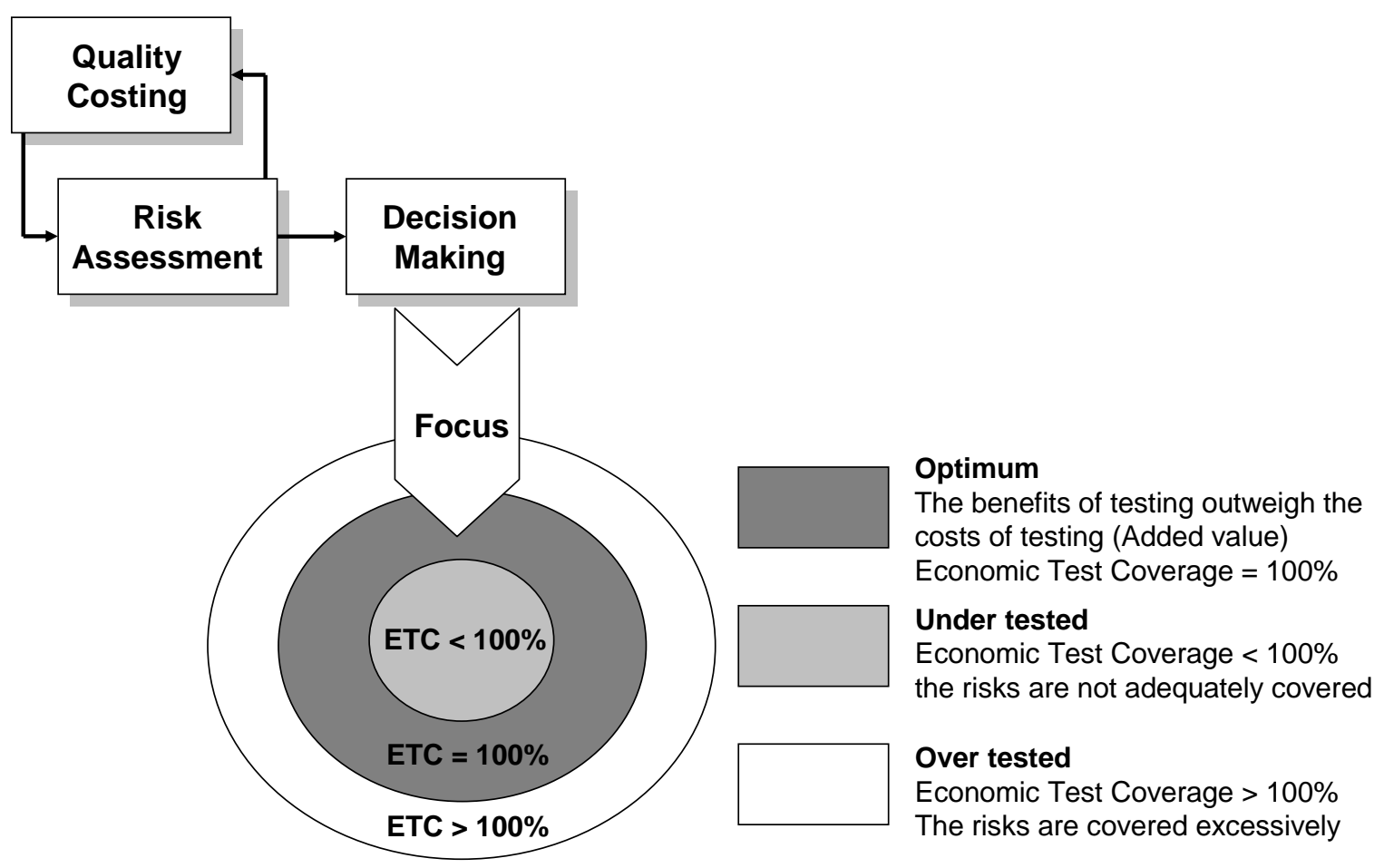

Fig. 6. Focus obtained by quality costing and risk assessment.

\section{Managing Testing and Maturity Models}

\section{Testing Needs to be Managed}

Testing activities are typically incorporated in a process model, which is parallel to the lifecycle models for product or system development. Modeling the development lifecycle permits a better recognition of possible defect injection points throughout the development project and 
optimization of the application of the available methods for defect detection and prevention i.e. quality assurance and testing. This approach works also in manufacturing environments, where the value chain can be easily recognized. There are separate testing lifecycles within other phases of the product process as well, but the test approach is not based on such an explicit value chain as in development and manufacturing. (Van Moll et al., 2002).

A testing lifecycle model facilitates the coordination of test efforts between the various "test levels" (groups of test activities directed and executed collectively (Pol and van Veenedaal, 1998)). A testing lifecycle model specifies the activities for each test level, and attempts to answer the questions what and when to test. However, consideration of testing lifecycles has mostly focused on the activities in the development stage of the product process (e.g. Belliveau et al., 2002; Cooper, 2001; Ulrich, and Eppinger, 2000), instead of considering the overall testing lifecycle involved in the whole product process (presented in Fig. 7), beginning at the research stage, up to after-sales. Even though each stage comprises its own testing lifecycle, the overall testing lifecycle would prevent sub-optimization within the discrete sub-lifecycles. The lack of an overall testing lifecycle can be seen as a reason for the deficient coordination of testing activities at organizational level (Pikka and Jokinen, 2003). 


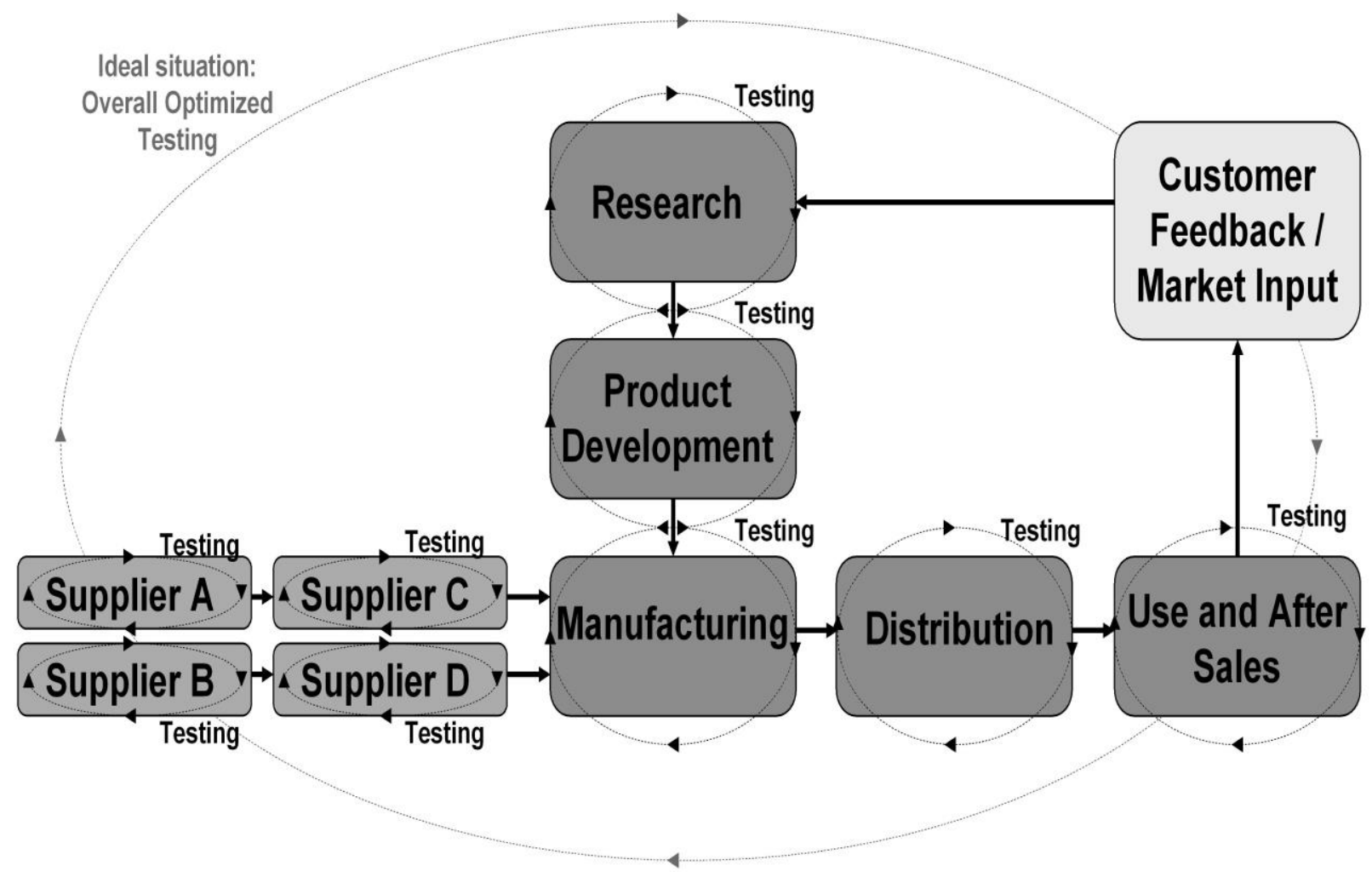

Fig. 7. Product process applied in the study. From sub-optimized testing to total optimization via an integrated testing lifecycle.

Deficient integration will lead to sub-optimization of testing operations, and will cause ineffective and inefficient overall testing performance. Thereby, a test strategy for the whole product process is required, incorporating the distinct testing lifecycles into a single entity with a common objective. Mutually conflicting objectives between separate stages can be solved only if the testing operations are examined in a wider scope. This approach permits consideration and optimization of the total added value of testing, instead of sub-optimizing within distinct separate stages.

Jablokow and Booth (2006) have noted how communication between separate stages provides a distinct business advantage by bringing together the diverse cognitive attributes necessary to 
solve the complex problems in high performance organizations. On the other hand, Patrashkova and McComb (2004) appreciate that highly qualified people may compensate for less overall communication, and that performance improves when the focus is on exchanging only the requisite pieces of information. Therefore, the management of testing through the product process would be easier due to better visibility over the operations of the other stakeholders, and through better communication of mutual problems and interdependencies. (Pikka and Jokinen, 2003).

\section{V2M2 Maturity Model}

The quality of testing is highly dependent on the quality of the overall test process. Deming's (1986) proposal for the definition of quality is: "The continuous improvement with aid of appropriate methods". Consequently, improving the quality of testing means focusing merely on the value-adding activities in a testing lifecycle. However, without making good improvement tool refinements to the processes, the test processes are not systematic (Staab, 2003). Therefore, improvements to the test process are needed with the aid of applicable methods, so that the approach will then become more systematic.

There are several existing models for test process improvement, yet the utilization of these models has been somewhat futile in most organizations. Various published studies (e.g. Staab, 2002; Swinkels, 2000; Weatherill, 2001) compare different improvement models. There are numerous reasons that have discouraged the implementation of the models in test process development. The most significant reason is the poor documentation available to implement and utilize the models fully, as most of the effort has been in marketing and selling consultancy 
services by introducing assessment models that do not provide any added value without the appropriate analysis tools. These tools are not available publicly (Weatherill, 2001).

Based on the findings in (Maatta, 2005), the V2M2 (Verification and Validation Maturity Model) model seems to be a comprehensive and thorough test process improvement model. The primary advantage of the V2M2 model is the universal applicability, meaning that it is not geared towards a specific type of business, such as software engineering, as most of the other test process improvement models are (Jacobs and Trienekens, 2002). The model is based mostly on TMM (Testing Maturity Model), which was developed earlier. Nevertheless, Ham et al. (2001) emphasize that there are several major differences between the V2M2 and TMM. In contrast to the TMM model, V2M2 has a (Ham et al., 2001):

- CMM /CMMI (Capability Maturity Model / Capability Maturity Model Integration) like structure also at the lower levels

- Comprehensive description of (sub)practices/maturity sub-goals

- Comprehensive glossary

- Test environment process area

- Organizational alignment process area

- Career development addition.

TMM, and also most of the other test improvement models, except the V2M2, overlooks the fact that the improvement actions of higher maturity levels cannot be performed independently from other organizational entities. To improve the testing process, the test organization has to be aligned with the Development department, Marketing, Sales, and so on. Therefore, processes require an increasingly wider scope at higher maturity levels and consequently require tuning 
and alignment with other functions and departments. This aspect has been involved in V2M2 model by introducing fundamental factors, such as people, technology, processes, and an organization. The fundamental factors are considered generic practices at each maturity level providing appropriate scope for improvements. (Jacobs and Trienekens, 2002).

The V2M2 framework is intended to increase the value of testing by improving testing maturity. The model shifts the focus onto value adding activities, and aims to increase the efficiency and effectiveness of testing, and to provide practical solutions for the improvement of the value adding activities. Empirical evidence is required to prove the validity of these statements and which should consider the costs associated with poor quality and testing, along with the maturity of testing. Considering the wider acceptance and utilization of any assessment and improvement models, the applicability and usefulness in terms of test process improvement should always be assured. Kessler (2000) suggests that managers need to pay attention to organizational capability factors to lower the development costs. Improving organizational capability is a part of the essence of the maturity models. Additionally, Nambisan (2002) sees maturity models (e.g. $\mathrm{CMM}$ ) as enablers for efficiency and quality assurance, through the establishment of rigor and discipline. A survey conducted by (Biberoglu and Haddad, 2002) on industrial experiences with CMM indicates that CMM-based process improvement is beneficial and pays off in the long-run, although further research is still needed on this issue.

Based on these findings, applying V2M2 for test process improvements could provide positive results, should the framework and the improvements be implemented properly, and should the management support these efforts accordingly. However, the implementation of a certain maturity model involves evident risks, which must be recognized in advance in order to prepare 
relevant counter-measures for the risks. In addition, Biazzo and Bernardi (2003) stress the importance of carefully assessing the models in order to find the one that best fits the organization's competencies and specific needs. Therefore, we propose further assessment of the V2M2 model to examine how this model affects the product lifecycle, how it relates to decreased time-to-market, financial optimization, and managing testing, and the test process more efficiently in general.

\section{Practical Challenges and Success Factors in Testing}

We conducted an empirical study into the status quo of managing the added value through the entire product process within the telecommunication industry, in order to obtain empirical evidence for the findings from the theoretical examination and discussions. The study approach is described below.

The empirical study consisted of ten interview sessions, comprising a representation from each phase of the innovation chain presented in this study. Five different companies from the telecommunication field were represented, two of which are globally among the top companies in wireless communication. One is a mid-sized European SW and HW business providing solutions for wireless and automotive industries and has representation and customers in numerous countries. One of the companies interviewed is a private Scandinavian distributor and supporter of wireless communication products and solutions, and another is a small national business that reprocesses electrical and electronic products. 
The participants volunteered to take part in the interview sessions and further selection was made carefully on the basis of their professional background and expertise. The criteria for each participant were as follows:

- to have many years of experience in the development of complex telecommunication products;

- to have a wide perspective of testing issues within the telecommunication industry;

- to be directly involved in testing operations.

Selected participants fulfilled the criteria described above and held responsible positions in the topics of the study. This ensured the high motivation among the participants and up-to-date knowledge and information with respect to the discussed topics. The job titles of the respondents include: Senior Test Manager (R\&D), Senior Test Manager (Manufacturing), Senior Developer (SW), Senior Process Manager (entire value chain), Test Manager (Manufacturing) x2, Senior Development Manager, Product Manager (Testing Business), Manager (Support Services), and Manager (Disposal). The selected participants were the top-professionals in the field of testing. In addition, we had executive level advice and support in the course of the study.

The preliminary assumptions are summarized as follows:

- changes in business environment and rapid technology development have complicated testing operations;

- test process integration and lifecycle modeling of testing are managed deficiently in terms of the entire innovation process;

- testing metrics are needed to manage the daily operations and to examine the impacts of test process changes on the testing performance and economics; 
- the current test operations maturity is not at an adequate level of maturity if compared to other company functions.

In addition to these assumptions, the aim was to inquire about the willingness to apply a maturity-based test improvement model in order to find out whether the organization finds maturity models useful and effective for improving the capability of testing functions. This is done to reveal possible obstacles regarding the implementation of the V2M2 or other test improvement models.

All the individual interview results were examined separately for each phase of the innovation process, so as to determine the differences between organizational units in managing testing activities. In addition, this approach provided a good insight into how the distinct phases have aligned and integrated testing at the organizational level. Fig. 7 earlier described the phases of the innovation process now covered for the interview results as well. It should be noted, however, that the suppliers have been left out for two reasons: 1) R\&D set the requirements for the testing activities of suppliers as well, and 2) suppliers can comprise such a large amount of actors that it is not feasible to go through them adequately. The phases in this study included: applied research, platform development, product development, manufacturing, after-sales and disposal.

The interview Questionnaire consisted of questions divided into four categories as follows:
A) Added value of testing
B) Test process management and lifecycle modeling
C) Testing metrics 


\section{D) Inquiry about usefulness of the maturity based test improvement model}

Appendix A contains the entire questionnaire. Questions included in these categories provide an understanding of the current situation within the industry, and reveals whether it is in line with the initial hypothesis. This part of the study was conducted by interviewing industry representatives of a limited number of distinct organizations, therefore it should be noted that the sample may not represent the universally applicable situation within this field. By having a wider set of organizations to be reviewed, the obtained results might have yielded a different analysis of contemporary testing operations within the telecommunication industry. A further study with a wider range of organizations remains to be completed in the future.

Outline: The interview sessions resembled conditions required for a high-quality study according to Yin (2003). He emphasizes that a researcher should be able to ask good questions and also interpret the answers. In addition, the researcher should be a good listener and not be trapped by his or her own ideologies or preconceptions. With these skills, the researcher is able to have an objective approach to research the problem and therefore obtain unbiased results in research.

The number of case interview sessions is not especially extensive. Yet, the nature of this study is not to confirm the present findings thoroughly, instead we aim to obtain further knowledge of the discussed topics. Therefore, additional interview sessions would not provide significant added value.

Interview process: Each interview session was based on the same questionnaire (Appendix A). Nevertheless, interviews were conducted informally allowing the interviewee to explain and 
clarify the cases and topics as entities. This approach enabled the researcher to obtain an extensive picture over the status quo, instead of dispersed and fragmented pieces of information. When necessary, specified questions were used in order to avoid misunderstandings, or to achieve a complete conception of the discussed topic.

\subsection{The added value of testing - (Section A on the interview)}

Global competition within the telecommunication sector has intensified and the changed environment drives the players to increase value-adding elements throughout the innovation process. Testing is one of those value-adding elements which has come under increasing pressure to provide enhanced added value. Aspects related to the changes in testing approach were examined in order to identify the value of testing within the telecommunication sector.

R\&D: Interviews proved that the characteristics of the telecommunication industry have elevated testing operations to a new position within R\&D. Developers, as well as the other stakeholders, understand the added value of testing relatively well. This, in turn, means that testing functions have encountered a clear transition from control culture to service culture, whereby consideration and development of testability issues can occur among the other functions. Nevertheless, R\&D does not necessarily know or understand the possibilities of the testing issues which could be offered in the latter phases of innovation process. The case interviews indicated that $R \& D$ could rationalize the testing operations among applied research, platform development, and product development, ensuring the maximized added value of testing. 
The different nature of hardware and software $R \& D$ functions reflects different approaches to testing operations. According to the interviewees, many aspects are easier to realize in hardware development than in software engineering.

Manufacturing: In the past, testing in manufacturing was based mostly on excessive inspections after the products were finished. First, R\&D provided specifications and requirements for the products to be developed, including specifications and requirements for testing. This was followed by the customers demanding specific inspections for the products they intended to buy. $R \& D$ was not convinced about the design requiring testing against design errors and customers did not trust the quality of manufacturing processes and demanded end-ofline inspections. The diverse measures and inspections conspired to enhance efficiency of testing leading to increased automation, although the circumstances led to excessive testing.

The case interviews show that nowadays, manufacturing has a totally different approach to testing due to changes in the operational environment. The added value of testing in manufacturing is based on the improved first time yield and increased capacity of production process achieved by effective process control, improved test and manufacturing methods, and improved component quality. Collected test data provides valuable information for process control and R\&D operations, preventing defects from re-appearing. Testing enables observation and location of defective units. Still, the ever increasing complexity of products challenges manufacturing testing for two reasons: 1) increasing technical complexity complicates accessibility, visibility, and control, and 2) additional features increase testing cycle time. 
After-sales: After-sales represents installation, maintenance and field service operations in this study. Organizations involved in the interview study have different type of products; this difference complicates the consideration of testing because testing is organized differently, depending on whether the company produces consumer products with a shorter lifecycle or business-to-business solutions having a considerably longer lifecycle. The volumes, increasing features, and diverse different products are the challenge in consumer products, whereas the complicated fault detection inconveniences are the challenge in business-to-business solutions. However, in both cases the added value of testing is based on an analysis of malfunction found by a specific tester and verification of repair of malfunctioning, yet the information obtained from the after-sales testing is also extremely valuable and essential.

After-sales testing has been seen as a necessary evil due to the inability to develop and manufacture reliable products. However, this is not a black-and-white issue as manufacturers aim to optimize the reliability of the products in relation to the costs. After-sales testing is an expense to the manufacturers, yet the warranty presumes the repair or replacement of a defective product. Thereby after-sales operations, testing included, are the customer service oriented activities, and the value accrues via customer satisfaction. Nevertheless, in business-to-business solutions, after-sales operations constitute a business unit, often bringing considerable revenue to the manufacturing company. Increased customer demands have constrained to enhance the reliability of the products and to boost the efficiency of after-sales operations. Nevertheless, testing generally enables the selection of the most cost-effective elimination of a malfunction in after-sales; whether it is by replacement or repair. 
Disposal: Testing in the disposal phase could provide added value by examining the reliability issues at the end of a product's lifecycle, e.g. certain components, repairs, and mechanics could be assessed in order to find out the weak and strong points in design or assemblies Disposal testing, especially, could open up the possibility of optimizing the reliability and provide information on how the evidently deficient items have lasted in use. Nevertheless, manufacturers seem to rely on after-sales operations to obtain the information regarding the reliability and durability. The disposal of electronic products concentrates on sorting out the exploitable and recyclable items and on removing the security threats from memories. The disposal phase is not discussed further in this study.

\subsection{Test process management and lifecycle modeling - (Section B of the interview)}

Test process management and testing lifecycle modeling were examined in this study in order to find out the differences and inconsistencies in test operations management, with respect to the entire innovation process.

R\&D: Organizations involved in this study have a project organization structure in place, so consequently, the development operations are supervised and controlled primarily within the development projects. This structure does not prevent establishing standard practices for testing operations, yet the interviews revealed that in some cases the projects may ignore the recommended practices in spite of risks related to changes. Testing practices within projects depend on the people responsible for the whole project and the people's professionalism or way of thinking affects the testing operations. In addition, parallel projects may encounter difficulties in synchronizing testing activities due to a number of constraints directing the schedules. 
Therefore test resources are sometimes scarce and compromises are made in testing. Tight schedules and project-specific goals also impede the exchange of information and lessons learned between projects. The case interview study addresses the evidence that the testing function requires better communication practices between projects. Additionally, more effective practices and processes are needed to enable cumulative learning in terms of former defects and errors.

Testing lifecycles within platform development and product development are usually distinct, depending on the nature of the products. Distinct lifecycles are required to coordinate the testing efforts in development projects. However, the case interviews indicated that the responsibility of certain tests evidently show that visibility and knowledge of execution between these phases are not always on record. On the other hand, there is still a past mindset present if one team or project is building the product entirely. Additionally, the product development completes some activities that should be shifted to platform development. Hence the existing overlap between these two phases should be avoided, as it is causing some parallel product programs to repeat the same tests, when could be done at once in platform development.

By considering the entire innovation process, test processes for both, platform and product development are integrated relatively well with the manufacturing operations. Nevertheless, the integration between these phases is not carried out completely with respect to testing. Although platform, or product development receive an input on some testability issues from the manufacturing phase, this input might be ignored due to some short-term objectives overtaking often more significant long-term benefits. Nevertheless, these cases are troublesome, because 
time-to-market is the driver, and limited resources do not allow the implementation of required changes without delays in product releases.

The connections to the applied research stage are not established particularly well either. The applied research stage could proactively begin to prepare the testing of applicable lead technologies ensuring defined and tested methods and infrastructure for latter testing operations. The case interviewees admitted that the research operations could examine more new test technologies as well.

Product development encounters further challenges with the products with a long lifecycle, where the new products are often updates to previous releases. Consequently, requirements for new product development and testing will be based, at least to some extent, on previous product releases. In this case, the interoperability of the old and the new product has to be verified in one way or another.

Even when product development begins to design a new product with an apparently clean slate, previously developed solutions, practices, mindsets, and processes follow up as a legacy. The interviewees indicated that these legacies sometimes complicate the implementation of new methods, technologies and practices. New practices must be prepared and justified thoroughly in order to ensure effective implementation.

Manufacturing: Generally, testing in the manufacturing stage has been managed efficiently and effectively for a long time because of high volumes and costs compared to R\&D. Yet, manufacturing often executes tests which could be performed earlier at the R\&D stage, or 
should not be executed at all, or could be performed more efficiently with BIST (Built in Self Test) features and other design changes. The case interviews revealed that manufacturing operations are increasingly examining the current testing methods and cases critically, aiming to remove unnecessary inspections and testers. The interviewees emphasized that manufacturing testing should focus primarily on manufacturing errors and failures in volume production. Test or pilot series are treated differently to improve the maturity of the product, and the test approach deviates from mass production.

Increased communication with $R \& D$ has enabled improvements to take place in the manufacturability, testability, and design of the products, decreasing the need for product specific testers and detection of design errors, and has also allowed manufacturing to set requirements with respect to testing. Typically, the manufacturing unit has a spokesperson in R\&D taking care of the testing and testability issues of the manufacturing phase. In consequence, manufacturing has been able to prepare the testing of new products and technologies proactively, thus facilitating 'rapid ramp ups', and avoiding unnecessary investment in production testers.

Even though manufacturing has relatively well-organized testing operations, the interviewees admitted that there is always pressure to improve the testing processes. The interviews revealed that the lack of comprehensive risk information complicates the decision making related to process control and proposed tests. Manufacturing aims to find a balance between testing costs and failure costs, but there is no exact information available on how to find the absolute optimum for testing. Thereby, certain risks are excessively covered, whereas others are not covered at all, causing unnecessary additional expenses. 
The interviewees wished for more attention on the tests that are imperative, in order to justify the true advantage of the tests. Some test cases are required merely just because those were done in the past without considering the benefit of the results. In addition, the interviewees criticized reporting the manufacturing test results purely on numerical format without any diagnosis or indicators. Therefore, a test specification process should specify in advance what needs to be tested and how, in order to avoid unnecessary testing and misinterpretation of the test results.

After-sales: The case interviews indicated that after-sales testing for consumer products is managed primarily well. The service points offering an authorized warranty service are supplied with product specific test software, enabling them to locate faults. Communication between the manufacturers and service points is arranged via intranet where information related to the specific problems of the products is available.

An increasing number of different products on the market complicate the service operations, requiring a variety of product specific tests, both SW and HW. Further, multi-purpose devices have such a variety of features that service personnel are required to study new products thoroughly in order to be able to determine the cause of the fault. The increased software applications are especially challenging because the service personnel have often a hardwarerelated background as a consequence of former requirements. Fault tracking in SW failures is more complicated than in HW related problems, hence adding to the challenge. Therefore, the increased use of SW has changed the operational environment of after-sales. 
The interviewees admitted that platforms assist in increasing the efficiency of after-sales testing. Products that use the same modules require less product specific tests, both HW and SW. Nevertheless, knowledge of the platforms used in certain products could be communicated better. Furthermore, the interviewees longed for more active interaction between after-sales, R\&D, and manufacturing. After-sales would like to receive responses to the given feedback, whereas $R \& D$ and manufacturing would appreciate a more accurate diagnosis and analysis of the faults.

The interviews also addressed the need for a more convenient installation of new applications and products. Currently, the installation phase requires a variety of special testers in order to verify the correct functioning of the installations. Many solutions that require a professional mechanic to install the specific devices could be performed faster and cheaper with a plug-andplay type convenience. Customers are now paying more attention to lifecycle costs requiring more convenient field services, especially when the solutions are critical to the customers' own business, and when it is not possible to stop using or disable them during the service.

\subsection{Testing metrics - (Section $\mathrm{C}$ on the interview)}

Test metrics and data gathering regarding the testing costs, testing failure costs, and defects are essential to manage and control testing function efficiently and effectively. Accurate data and relevant metrics provide information for decision making in relation to the quality of products and processes. Otherwise the release decisions, further investments, and process changes are troublesome to justify without appropriate information. 
R\&D: Platform and product development involve an enormous amount of testing. Therefore, management and control of all the testing-related activities are challenging. The case interviews prove that practices related to metrics and data gathering differ among the examined organizations and between the discrete phases in R\&D. In places, the testing cost factors are quite well identified, specified and monitored, whereas elsewhere testing costs are based on approximations and evaluations of the total $R \& D$ costs. Nevertheless, interviews addressed the shared trouble of clearly pointing out the testing efforts from development efforts.

The interview study confirmed that there is enough data available on the failure costs and defects in R\&D but the actual problem is the utilization of this data. Usually, all the rework, redesign, and retest are recorded but the monitoring of follow-up data is deficient. Interviewees admitted that many mistakes are repeated causing the same defects and failures in new projects. There are certain clear signals such as warranty costs and FFR (Field Failure Rate) which give feedback to development stages, yet these are indicators and actions definitely too late to correct and adjust during the development. Additionally, due to delayed feedback the actual root causes may be difficult to track down, if there is time to look at the past projects. Hence, the projects should be supplied with failure indicators facilitating the immediate solution of problems and their recurrence. All the required data is available, but the various indicators should be arranged properly to provide meaningful guidelines.

A lack of specific indicators prevents the setting of accurate objectives for the development of testing methods. Consequently, objectives for the progress of the entire testing function within development stages cannot be allocated effectively, because the indicators and objectives at a 
lower level are deficient or missing. Certainly, the objectives for the total costs for testing within a certain project can be planned, but monitoring and controlling the cumulated costs during the project is difficult, if not impossible. Due to all retests involved in the rework and redesign, the initial tests are multiplied together with the budgeted costs. In the end, the total testing-related costs can be calculated after the project is finished. However, such calculations afterwards are troublesome and laborious and, consequently, tempting to skip altogether.

Manufacturing: the manufacturing metrics include sound indicators of testing costs, failure costs, and defects. High volumes have constrained to focus on metrics in order to ensure efficient, effective, and high quality operations. Progress with respect to testing is monitored on a financial basis, but monitoring improvements related to the increased effectiveness and efficiency of testing is deficient.

Testing costs in manufacturing are based on the cycle time of executed tests per product. Investments in testers are monitored against the obtained capacity, coverage, and cycle times, so that payback can be calculated by comparing them to the previous systems. Objectives for testing costs are set, but the trend in costs is not always considered because the testing costs are just a factor among a variety of others. Manufacturing testing has to be paced with the other operations on the production line, thus testing cycle time is not an issue if it does not constitute a bottleneck for the line. Neverthesless, capacity is the driver in manufacturing, forcing testing to be fitted accordingly. Thereby, testing costs can be optimized within the demanded capacity.

Production yield is a primary indicator for testing failure cost in manufacturing. However, yield is not really a sensitive indicator that provides diagnosis of specific type of defects; rather it 
gives feedback about the overall healthiness of manufacturing processes. Therefore, the interviewees revealed that failures are going to be monitored more specifically by Six Sigma based DPMO (Defects per Million Opportunities) measures in order to obtain more accurate data about failures and failure costs. Although testing failure costs are followed up somewhat systematically, objectives for decreasing these costs are set inconsistently. This indicates that manufacturing failure costs are at a reasonable level allowing certain failures, but high manufacturing volumes carry considerable costs at any failure rate. Therefore specific objectives for decreasing failure rates in manufacturing could bear savings in the long term.

Manufacturing defects are usually indicated by TOP 5/TOP 10 listings, or on Pareto charts. The root causes for injected defects are analyzed depending on the importance of the defects and availability of resources. Instructions as well as methods for analysis are not established, neither are rules when the certain defect type is severe enough to be solved immediately. Statistics on typical defects in the longer term are not generated and controlled systematically; rather the knowledge is based on the perceptions of certain people. Non or late detection of defects is analyzed according to the severity and occurrence of the phenomenon, yet the interviewees called for more accurate data in the case of field failures. Otherwise it is impossible to analyze whether the defect is a manufacturing error, design error, or neither.

After-sales: The metrics of after-sales testing in consumer products are mostly based on information obtained from external warranty service points. Business-to-business solution providers have a distinct business unit managing after-sales testing operations, which takes care of the information related to metrics as well. The total costs related to warranties, maintenance, and other field services are well known although an accurate picture of the testing costs involved 
cannot be specified. Typically, after-sales tests require extensive test coverage in order to trace the actual root cause of the failure. The efforts required often depend on the competence of the personnel, and the quality of testing and problem-solving is not equal. Sorting out the costs caseby-case is not feasible and involves the use of rules of thumb, rather than exact costs.

Defect data related to after-sales operations are established relatively well by completing failure reports in repairs. In consumer products skilled service personnel are capable of providing accurate diagnosis on failures. The interviewees reported that business-to-business solutions are often too complicated and prevent the field service personnel from identifying the root causes of the failures; therefore delaying the feedback loop from after-sales to R\&D and manufacturing, due to additional diagnosis by a separate group of professionals. For that reason the field service operations could be enhanced by more effective self-testing embedded into the products.

\subsection{Testing Maturity - (Section D of the interview)}

Challenges faced throughout the testing life cycle and identified during the interviews reflect the current state of testing maturity with respect to the organizations examined. The interviews indicated that the maturity of testing operations varies significantly between the separate phases of the innovation process, e.g. manufacturing and has relatively sound metrics in use allowing proactive control of the yield with reasonable accuracy, whereas R\&D may not have any metrics for certain testing operations. The results obtained for different functions are combined here into one group due to the interviewees indicating that similar factors affect the testing maturity in all of the studied functions. These factors are as follows: 
Integration: In order to continue improving the testing, remedies for the current challenges need to be assessed and prioritized. Clarifying the goals of testing at each level of action would remove its dependence on certain individuals and therefore assure a more predictable outcome from the processes, no matter who manages them. Hence, the integration would bring a systematic approach to testing with minor efforts.

Communication and information management: Communication and information management are other contributory factors enabling to increase the current maturity of testing. In part, improved communication enhances the integration of the testing function, whereas an integrated testing function assures better communication. The development of communication and information management practices presents a challenge, but when applied effectively they would provide an effective tool to keep on track with respect to goals and objectives. Testing operations resemble logistics, in terms of dispersion of operations across the entire innovation process.

Metrics: The interviews indicated a vital need to obtain meaningful information, instead of a variety of separate indicators, to enhance the daily management of testing activities.

Solid lifecycle: One difficulty in achieving an integrated testing function is the discrete testing lifecycles, involved in the separate phases of the innovation process. These separate cycles often have conflicting objectives. 


\section{Maturity models for test improvement:}

The industry representatives have had relatively little experience of any maturity models aimed at assessing and improving the capability of processes. Most of the interviewees have heard of, or have studied, CMM or CMMI but testing maturity models were unfamiliar to most of them. One interviewee was familiar with TPI, but V2M2 was unfamiliar to the industry representatives.

The interviewees were familiarized to the concept of the testing maturity model in order to obtain an adequate understanding of the implications of implementing a certain kind of maturity model. The interviewees have a good picture of the required efforts and risks related to the implementation of such a maturity model. The interviewees accepted the benefits of applying a maturity model to increase the capability of the testing processes, but all were skeptical about the eventual payback of the investment. The biggest problem according to the interviewees was the resistance against the required changes in practices demanded by the maturity models. In general, maturity models can be implemented only in such conditions where there is no other alternative. Relatively stable conditions do not encourage applying any remarkable changes other than fine-tuning the processes and practices.

Despite the doubts related to the implementation of the maturity model for testing, one interviewee admitted the usefulness of management being familiar with such maturity models so as to address weak points and improvements. Nevertheless, the case organizations do not provide training or any other support to increase the utilization of maturity models at any level. The advantages of implementing a certain maturity model partially or unsystematically are limited and unpredictable, preventing to obtain integrated practices for evaluations and process improvements across the units or an organization. 


\subsection{Challenge and Success Factors of Testing}

\section{Testing challenge factors}

During the course of the interviews, certain aspects that complicated the improvement of testing operations, or prevented an increase of the testing maturity, emerged repeatedly. Even though the interviewees worked in separate units, common factors seemed to exist in terms of testing. Those factors are recorded as testing challenge factors, of which are: the operational environment, know-how, culture, organization, and legacy findings. These factors are explained further in Table 1. Additionally, Table 1 contains a few sub-factors encountered as the same time as the challenge factors. The list is not exhaustive, yet it contains examples of most frequent aspects and elements.

\section{Table 1}

Testing challenge factors identified during the interview study.

\begin{tabular}{ll}
\hline Testing challenge factors & Sub-factors \\
\hline Legacy findings & Legacy designs \\
& Legacy processes \\
& Legacy methods \\
& Dispersed sites \\
Organization & Different backgrounds \\
& Deficient test management \\
& Separate projects \\
& Dependence of individuals \\
& Multi/ Cross-functionality \\
& \\
Culture & Readiness for change vs. resistance for change \\
& Rallying points vs. distinguishing points \\
& Mutual understanding \\
& Best practices/ competence \\
Know-how & Methods and techniques \\
&
\end{tabular}


Metrics and indicators

Quality and risk level

Suitable data

$\begin{array}{ll}\text { Operational environment } & \text { Fast technology change } \\ & \text { Fast growth --> mature phase } \\ & \text { Increasing complexity of the products } \\ \text { (technical/ features) } & \text { Short-term objectives }\end{array}$

\section{Operational environment}

The case interviews proved the effect of the operational environment on the testing function, which can stabilize and rationalize testing operations.

\section{Know-how}

The interviews indicated that know-how and competence with respect to testing is not at the best possible level. Needs for certain improvements were partially identified, but best practices in relation to legacies have not been implemented effectively to obtain a better performance.

\section{Culture}

The corporate culture puts a significant value on the state of change. How the employees look at the changes and the level of willingness or resistance towards the intended changes, are crucial in implementing new methods or practices. The interviews proved that the success of the changes depends on these cultural factors, which are difficult to control.

\section{Organization}

The interviews addressed many organizational phenomena that complicate the improvements and daily operations. The challenges faced require further examination, more than just the 
difficulties related to the testing operations. However, testing can be seen as a shared function incorporating separate units into one single entity, thereby the challenges and difficulties related to the organization should be examined also in a testing context.

\section{Legacy findings}

A common statement, which the interviewees have heard or claimed, was that some things are done in a particular way regardless of whether it is the best way. Legacy methods, processes and designs are not unfavorable issues so long as they can be examined critically. There are certainly many good practices existing, but changing conditions involves ongoing improvements. Often small, gradual changes are the best way forward, and re-engineering should be kept for cases of crisis.

\section{Testing success factors}

The above mentioned challenge factors desperately need a remedy to be treated and improved effectively. The interviewees proposed certain counter-measures to overcome the challenge factors, and thus bring about an increase in testing maturity. These counter-measures are presented as testing success factors and are, namely: integration, rationalization, leadership, communication, and change management. In addition to these proposed courses of treatment, the authors have added some factors and sub-factors that arose from the theory part of this study. The list in Table 2 is not exhaustive but illustrates some examples of aspects and elements related to success factors.

\section{Table 2}

\section{Testing success factors identified in interview study.}




\begin{tabular}{ll}
\hline Testing success factors & Sub-factors \\
\hline Change management & New mindset \\
& Implementation of changes \\
& Adherence to changes \\
Communication and & \\
information management & Objective/ goals \\
& Metric/ indicators \\
& Data gathering \\
& Inputs/ outputs \\
& Reporting \\
& Responsibility \\
& Ownership \\
& Commitment \\
Leadership & Rewarding of achievements \\
& \\
& Common methods, techniques, and automation \\
& Resources \\
& Processes \\
& Product architecture (SW/ HW platforms) \\
& Systematic practices \\
Rationalization & Discrete testing lifecycles \\
& Testing policy \\
& Testing technologies \\
Metrics - balanced scorecard
\end{tabular}

\section{Integration}

Integration comprises several issues to be considered, and all the other success factors contribute to the integration of discrete testing lifecycles in the innovation process. Nevertheless, should the integration of testing have some fundamental principles at the beginning, it would assure a shared vision of goals and objectives regarding the entire innovation process. Integration is crucial for being able to optimize added value in testing as a whole. Integration assumes that distinct organizational entities understand the interdependencies between each other in order to obtain an appropriate input for testing, resulting in a desired output. The interviews revealed that a lot of work has to be done to meet these diverse challenges in the case organizations. 


\section{Rationalization}

The interviews raised the need for rationalization in testing activities at various levels. Separate units with similar tasks often employ different tools and methods, requiring multiple efforts to maintain and become familiar with, while also preventing interoperability of the deliverables and preventing an exchange of views on testing tools and methods. Divergent practices lead to an inefficient use of resources and can incur misinterpretations.

\section{Leadership}

The interviewees presented the need for leadership in order to implement a new mindset and new practices in testing. The interviews showed the need for a certain party who would communicate the benefits, possibilities, and feasibility of the proposed improvements to others. This party could either be a single business unit or a particular phase of the innovation process.

\section{Communication and Information management}

Addressing the deficient communication and information management at various levels is a key factor for dealing with the sub-optimization of testing. The interviewees admitted that a lack of knowledge and information is a strong contributor to sub-optimized decisions. Deficient communication causes excessive failures and costs due to misinterpretations and misunderstandings of test results, implicit assumptions, lack of trust, and wasted time in searching for information.

\section{Change management}

Change management is required to be able to implement improvements efficiently and effectively. Change is constant in the telecommunication industry even though many practices and mindsets remain unchanged. Change management is crucial in order to integrate, harmonize, 
and align testing operations across the multiple organizations and to ensure complete implementation of the assigned changes and improvements.

\section{Discussion}

The study highlights the importance of having fresh views and an open mind on the management of testing. The discussion is based on the changing business environment in telecommunication industries, where the current trends of growing complexity and decreased time-to-market have raised the importance of testing. The different types of testing (HW, SW, $\mathrm{V} \& \mathrm{~V}$, and so on) need to be viewed from the management viewpoint to be able to obtain the best possible cost effectiveness via more efficient and concrete metrics and decision making. The significance of testing is examined with regard to quality costing and risk assessment, assessing the theoretical impact of maturity on the testing activities, and the use of an optimization model for managing testing is recommended. The tangible measure for the testing activities could be the Economic Test Coverage (ETC).

The current level of managing testing activities is not at the level it should be and the findings of the empirical study prove that the overall maturity of testing is not at an adequate level. The current testing activities are not structured and managed as an overall process throughout the product process. If there is a need for improvement, it may be difficult while the organizations are commercially successful, wrongfully indicating that the products are "good enough". An increase in maturity would require diverse actions, which depend on the current state of the 
organization. However, the identified challenge and success factors listed in this article provide a starting point for identifying needs for further analysis. The current testing activities are suboptimized, causing overlapping, inefficiency and waste of resources. Testing as a function is lacking behind other business functions, and too little management attention is being paid to these activities. Furthermore, the individual responsibilities are not clear and the importance of these functions is not generally understood. Better management appreciation and general understanding of the importance of testing activities are the single most important factors for improvement, to remove the sub-optimization. Designing and embedding the overall testing lifecycle into the product process (including services) would clearly be beneficial for the overall business, allowing better control and management of these activities.

Risk-based testing and quality costing are necessary to optimize testing, based on our holistic view, because when they are utilized together, they provide information and support for decision making. They can be used to assess and measure the accurate value of testing related to quality risks. Risk based testing and quality costing can be utilized to create meaningful metrics for management purposes. One possibility for the metrics is to measure testing activities via the Economic Test Coverage (ETC), which would give a percentage based estimate, comparing testing costs and failure costs in an attempt to identify the optimum. This type of measure is theoretically relevant. The empirical research confirms the need for meaningful metrics, so that decisions can be based on something more concrete, not merely on experience or "gut feeling". Nevertheless, further research is required to confirm the empirical findings.

Maturity models can be utilized for managing testing activities to obtain a more comprehensive management control at different levels of maturity. The requisite management attention varies 
at different levels of maturity. Theoretically, increasing testing maturity has a positive impact on the cost of failures and testing activities. Based on the findings of this study, the V2M2 (Verification Validation Maturity Model) can bring positive results. After studying the benefits of improved maturity, we believe that the maturity of testing can be improved by learning from the different development models. However, maturity models in general were somewhat foreign to the interview participants, when the interviewees were asked about the usefulness of these models. The representatives of telecommunications industries resisted the adoption of these models, and regarded them as a last option in crisis circumstances. Therefore, the model to be utilized would have to be more defined from a practical viewpoint and further empirical evidence is required for this.

In the empirical study we identified five testing challenge factors (legacy findings, organization, culture, know-how, and operational environment), which impede obtaining added value, and thus prevent an increase in testing maturity. The identified challenge factors call for improvements in the management of testing issues. The current level of competence of test management is not enough to create a disciplined and controlled test management stream across the entire product value chain. The results show how test management lacks tools, authority, and expertise to harness testing operations under better control. Testing is often directed by incorrect and unrelated information, or an organizational body, inducing overlapping, misunderstandings, lapses, and inefficiency, resulting in a waste of resources in testing. The V2M2 maturity model could provide a pragmatic solution to the challenge factors. We identified five testing success factors (change management, communications and information management, leadership, rationalization, and integration/alignment), which contribute to overcoming the challenge factors, hence enabling an increase in testing maturity. Enhanced maturity of testing can be converted 
into enhanced added value as well. This can be obtained by concentrating on the identified testing success factors. The individual challenges and success factors obtained in the course of the empirical study can be interpreted as business success factors.

The use of selected sources can be well justified and was adequate to answer the research questions in a suitable manner. The material used for the theoretical part of this study was complemented by industry interviews, and was constructed in a manner to allow critical discussion during the process. Some of the findings of this study can be extrapolated beyond the scope of the study and the results are reliable, as similar results would be obtained if the same sources were used and the logic behind this study is repeated. However some variation could be expected if the interviews were conducted on a larger scale.

The results obtained in this study were in the field of the telecommunications industry. Nevertheless, they may be applicable to the whole range of ICT (Information and Communications Technology) industries. The type of testing discussed is not specific to any particular type of testing, the viewpoint is non-technical, and the intention was clearly to portray a management perspective. The results obtained clearly confirm the significance of having tangible metrics on testing activities, and how increased management interest and attention needs to be paid to these activities. The study also indicates that further testing research is required to enhance the capabilities of current testing processes. 


\section{APPENDIX A}

\section{Questionnaire - Added Value in Testing Lifecycles}

\section{A) The added value of testing}

1. What is the role and significance of testing in your business unit at the moment?

2. How has the testing function evolved in your business unit in the past?

3. What are the main reasons for the changes in testing, if any have been made?

\section{B) Test process management and lifecycle modeling}

1. How is the test function managed, coordinated, and organized within your business unit?

2. Does your business unit receive input for testing, and if so, how well does the received input satisfy the need for input?

3. How has your business unit defined an overall test approach?

4. How does the current overall test approach facilitate the coordination and optimization of testing regarding the project-specific lifecycle?

5. What is needed to understand better the dependencies of testing activities between the distinct stages of the innovation process? 


\section{C) Testing metric and data gathering}

\section{C1) About managing and monitoring testing costs}

1. How precisely are testing cost factors identified (tools HW/SW, environments, training, labor, suppliers)?

2. How precisely are testing cost factors specified and gathered (management, planning, preparation, execution, recording, analysis)?

3. How is the gathered data utilized?

4. What additional data should be gathered?

\section{C2) About managing and monitoring testing failure costs}

1. How precisely are failure cost factors identified (rework, retest, yield loss, warranty costs, product recalls)?

2. How precisely are cost factors specified and gathered (lack of planning, expertise, time, resources, information)?

3. How is the gathered data utilized?

4. What additional data should be gathered?

\section{C3) About gathering defect data}

1. How is the data about typical defects within each phase of the innovation process gathered and made available? 
2. How is the data about typical causes for the injection of defects analyzed and gathered?

3. How is the data about typical causes for non- or late-detection of defects analyzed and gathered?

4. How is the gathered defect data reviewed to find locations of defect sensitive areas and weak points for defect detection?

\section{D) Inquiry about usefulness of the maturity based test improvement model}

1. Do you have any experience of maturity based improvement models?

2. Your opinion about the need and benefits of maturity model for test improvement? 


\section{References}

Abramovici, M., Breuer, M.A, Friedman, A.D., 1990. Digital Systems Testing and Testable Design, Computer Science Press, NY.

Ahern, D.M., Clouse, A., Turner, R., 2004. CMMI Distilled, A Practical Introduction to Integrated Process Improvement, 2nd edition, Addison-Wesley.

Andersson, C. and Runeson, P., 2002. Verification and validation in industry - a qualitative survey on the state of practice, Empirical Software Engineering, 2002 Proceedings. International Symposium.

Bach, J., 1999. "Risk-based testing - How to conduct heuristic risk analysis," Software Testing \& Quality Engineering [Available online], <www.stqemagazine.com>, 1999, Read 12.10.2004.

Bate, R., Kuhn D., Wells C., 1995. A Systems Engineering Capability Maturity Model (SECMM), Software Engineering Institute.

Belliveau, P., Griffin, A., and Somermeyer, S., 2002. The PDMA ToolBook for New Product Development, John Wiley \& Sons, New York.

Biazzo, S., and Bernardi, G., 2003. Organizational self-assessment options: A classification and a conceptual map for SMEs, International Journal of Quality \& Reliability Management, Volume 20 Number 8.

Biberoglu, E., and Haddad, H., 2002. A survey of industrial experiences with CMM and teaching of CMM practices, The Journal of Computing in Small Colleges, Volume 18, Number 2.

Black, R., 2004. Critical testing process - Plan, Prepare, Perform, Perfect, Addison-Wesley, Boston. 
Brown, F.B. and Kane, R.W., 1984. Quality cost and profit performance. In: J. Campanella, Editor, Quality costs ideas and applications, ASQC Press, Milwaukee, WI.

Burns, M., and Roberts, G.W., 2001. An Introduction to Mixed-Signal IC Test and Measurement, Oxford University Press, New York.

Burnstein, I., 1996. Developing a Testing Maturity Model, Illinois Institute of Technology.

Chrissis, M.B., Konrad, M., Shrum, S., 2003. CMMI Guidelines for Process Integration and Product Improvement, Addison-Wesley.

Cooper, R., 2001. Winning at New Products, Perseus Publishing.

Davis, B., 1994. The economics of automatic testing, McGraw-Hill Book Company, London.

Deming, W.E., 1986. Out of the Crisis - Quality, Productivity and Competitive Position, Cambridge University Press, Cambridge.

Dulaney, K., Wood, B., Hafner, B., 2005. Predicts 2006: Mobile Terminals to Become More Complex, More Competitive. Gartner Research, http://www.gartner.com.

Feigenbaum, A.V., 1961.Total quality control, McGraw-Hill, New York.

Gilb, T. 2005. Competitive Engineering: A Handbook for Systems Engineering, Requirements Engineering, and Software Engineering Using Planguage, pp. 480, Elsevier

Griffin, A. 1997. Modeling and measuring product development cycle time across industries, Journal of Engineering and Technology Management, Volume 14, Issue 1, March, p. 1-24

Ham, M., Jacobs, J., Swinkels, R., and Van Veenendaal, E., 2001. Metric Based Testing Maturity Model Framework v1.1, [Available online], <http://tmitwww.tm.tue.nl/research/v2m2/>, Read 22.11.2004.

Harrold, M.J., 2000. Testing: a roadmap, Proceedings of the conference on the future of Software engineering, ACM Press New York, NY, USA. 
Jablokow, K. W. and Booth D. E. 2006. The impact and management of cognitive gap in high performance product development organizations, Journal of Engineering and Technology Management, Volume 23, Issue 4, December, p. 313-336

Jacobs, J., and Trienekens, J., 2002. Towards a Metric Based Verification and Validation Maturity Model, [Available online], <http://www.springerlink.com/media/78U409GQRGCUUV9RFL1Y/Contributions/N/9/Q/V /N9QVQDMF6AD886Y1.pdf>, Read 25.11.2004.

Jahangiri, J. and Abercrombie, D., 2005. Value-added defect testing techniques Design \& Test of Computers, IEEE Volume 22, Issue 3, May-June.

Jokinen, T., and Maatta, J., 2005. Keynote: "Defining the essential terms in testing”, IEEE European Board Test Workshop 2005, Tallinn, [Available online], <http://www.dft.co.uk/EBTW2005/PAPERS/ebtw05-0-2-Keynote-Jokinen-OuluUniv.pdf>, cited 13.1.2006.

Jokinen, T., 2006.Challenges of Managing Testing in Wireless Communications. Presented by Tauno Jokinen (University of Oulu) at GIGA-annual seminar on 11th September 2006 at Finlandia House in Helsinki.

Kessler, E. H. 2000. Tightening the belt: methods for reducing development costs associated with new product innovation, Journal of Engineering and Technology Management, Volume 17, Issue 1, March, p. 59-92

Kit, E., 1995. Software Testing in the Real World - Improving the Process, Addison-Wesley, Wokingham.

Krause, M.H., 1994. a Maturity Model for Automated Software Testing, Medical Device \& Diagnostics Industry Magazine. 
Kung, D.C., Hsia, P., and Gao, J., 1998. Testing object-oriented software, IEEE Computer Society Press Los Alamitos, CA.

Landers, T.L., Brown, W.D., Fant, E.W., Malstrom, E.M., and Schmitt, N.M., 1994. Electronics Manufacturing Process, Prentice Hall, Englewood Cliffs.

Moen, R.M., 1998. New Quality Cost Model Used as a Top Management Tool, the TQM Magazine, Volume 10, Number 5.

Myers, G.J., 1976. Software Reliability - Principles \& Practices John Wiley \& Sons Inc., New York.

Maatta, J., 2005. Managing Testing Through the Innovation Lifecycle from Research to Disposal. University of Oulu. (Master's Thesis) [Available online] <http://www.ntcforum.org/index.php?785>

Mottonen, M. Jokinen, T. Belt, P. Harkonen, J. 2006. Optimization Model for Production Test Management. Nordic Test Forum (NTF'06), Tuusula, November 28-29.

Nambisan, S. 2002. Software firm evolution and innovation-orientation, Journal of Engineering and Technology Management, Volume 19, Issue 2, June, p. 141-165

Oakland, J., 2000. TQM - Text with Cases, 2nd Edition, Butterworth-Heinemann, Oxford.

Patrashkova, R. R. and McComb, S. A. 2004. Exploring why more communication is not better: insights from a computational model of cross-functional teams, Journal of Engineering and Technology Management, Volume 21, Issues 1-2, March-June, p. 83-114

Perttula, A., 2004. New approaches to improve verification \& validation methods to fulfill the needs of fast and high volume consumer mobile terminal development. Proceedings of NordDesign 2004: Product Development in Changing Environment. Tampere, Finland, 1720.8.2004. 
Perttula, A. 2007. Challenges and Improvements of Verification and Validation Activities in High Volume Electronics Product Development, $\mathrm{PhD}$ dissertation, Tampere University of Technology, Finland. Publication 650

Pikka, V. and Jokinen, T., 2003. Testing in Electronics Industry within Oulu Region (in Finnish), University of Oulu Finland (unpublished)

Pol, M., and Veenendaal, E., 1998. Structured Testing of Information Systems - an Introduction to TMap, Kluwer BedrijfsInformatie, Deventer.

Porter, L.J. and Rayner, P., 1992. Quality Costing for Total Quality Management. International Journal of Production Economics, 27. Elsevier Science Publisher B. V.

Redmill, F. 2005. Theory and practice of risk-based testing, Software Testing, Verification and Reliability, Volume 15, Issue 1, p. 3-20, John Wiley \& Sons

Rumney, M. 2003. Position statement by panelist Moray Rumney of Agilent Technologies, International Test Conference, ITC 2003 Panel Discussion Testing 3G-controlled systems: time to rejoice or time to feel pain? [Available online] <http://csdl2.computer.org/comp/proceedings/itc/2003/2063/00/20631322.pdf>

Schiffauerova, A. and Thomson, V., 2006. "Managing cost of quality: Insight into industry practice”, The TQM Magazine.

Sippola, K., 2000. Quality Cost Measurement as a Tool for Top Management in Contemporary Software Business Environment, University of Oulu.

Staab, T.C., 2003. Improving the Test Process - Looking at the Test Process - Getting Started, The Journal of Software Testing Professionals, March 2003. [Available online]. <http://www.windridgeinternational.com/Improving\%20the\%20Test\%20Process\%201.pdf>, Read 22.11.2004. 
Staab, T.C., 2002. Using SW-TMM to Improve the Testing Process, Crosstalk, The Journal of Defence Software Engineering, November, pp. 13-16.

Swinkels, R., 2000. A comparison of TMM and Other Test Process Improvement, Models, [Available online], <http://tmitwww.tm.tue.nl/research/v2m2/wp1/12-4-1-FPdef.pdf>, Read 22.11.2004.

Van Moll, J.H., Jacobs, J.C, Freimut, B., and Trienekens, J. 2002. The Importance of Life Cycle Modeling to Defect Detection and Prevention, Software Technology and Engineering Practice. STEP 2002. Proceedings. 10th International Workshop on, 6-8 Oct.

Weatherill, T., 2001. In the Testing Maturity Model Maze, The Journal of Software Testing Professionals, Volume 2, Issue 1.

Ulrich, K. and Eppinger, S., 2000. Product Design and Development, McGraw-Hill, New York. Woodward, M.R. and Hennell, M.A., 2005. Strategic Benefits of Software Test Management: a Case Study, Journal of Engineering and Technology Management, Volume 22, Issues1-2, March-June.

Yasin, M. M., Czuchry, A. J., Dorsch, J. J. and Small, M. 1999, In search of an optimal cost of quality: an integrated framework of operational efficiency and strategic effectiveness, Journal of Engineering and Technology Management, Volume 16, Issue 2, June, p. 171-189 Yin, R.K, 2003. Case Study Research - Design and Methods, 3rd Edition, Sage Publications, Thousand Oaks, $181 \mathrm{p}$. 


\section{Tables and figures}

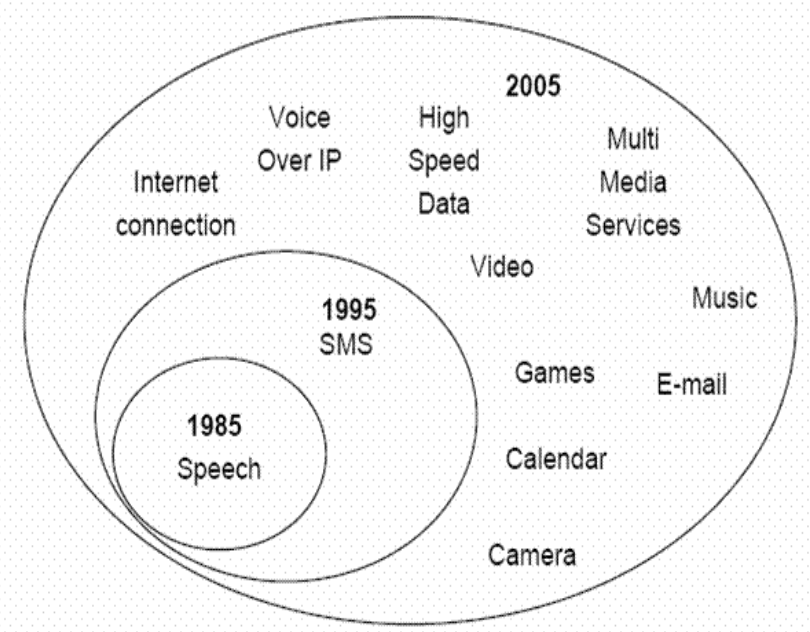

Fig. 1. The increasing complexity of mobile products (Modified from Jokinen, 2006) 


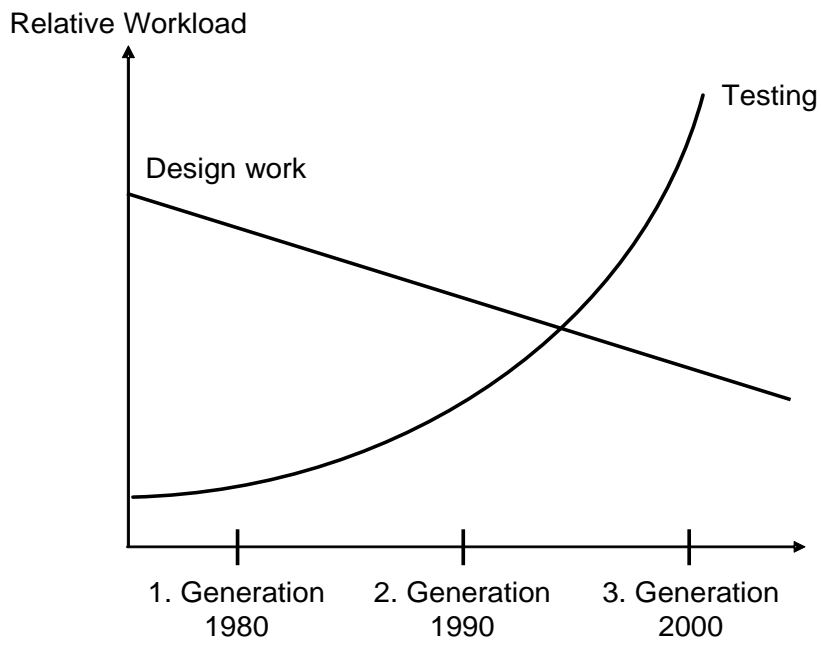

Fig. 2. Relative workload of the telecommunication product development, while the design work has become more effective (Modified from Jokinen, 2006) 


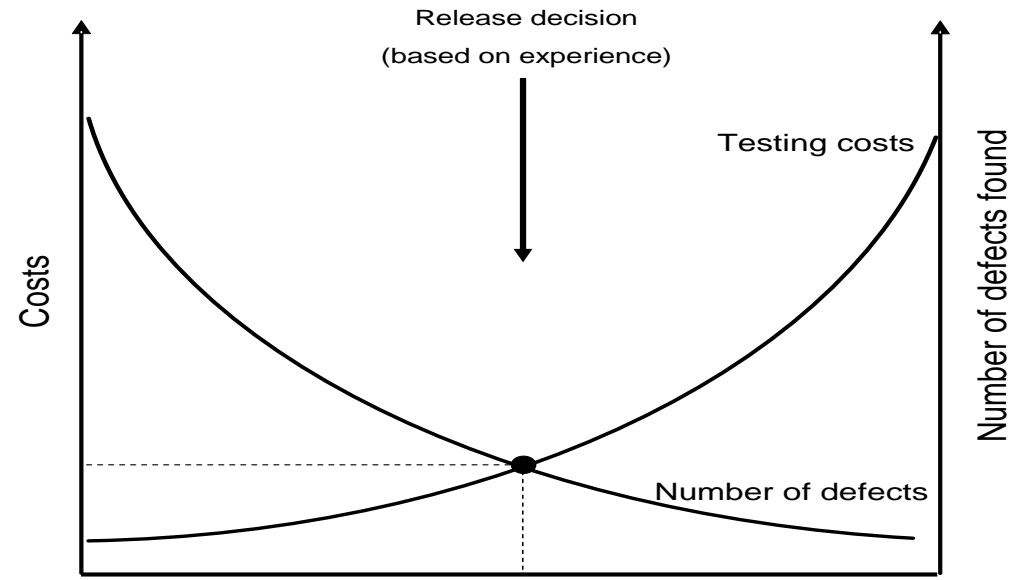

Time spent in development \& testing

Fig. 3. A way of estimating the optimal release decision point (Brown and Kane, 1984). 


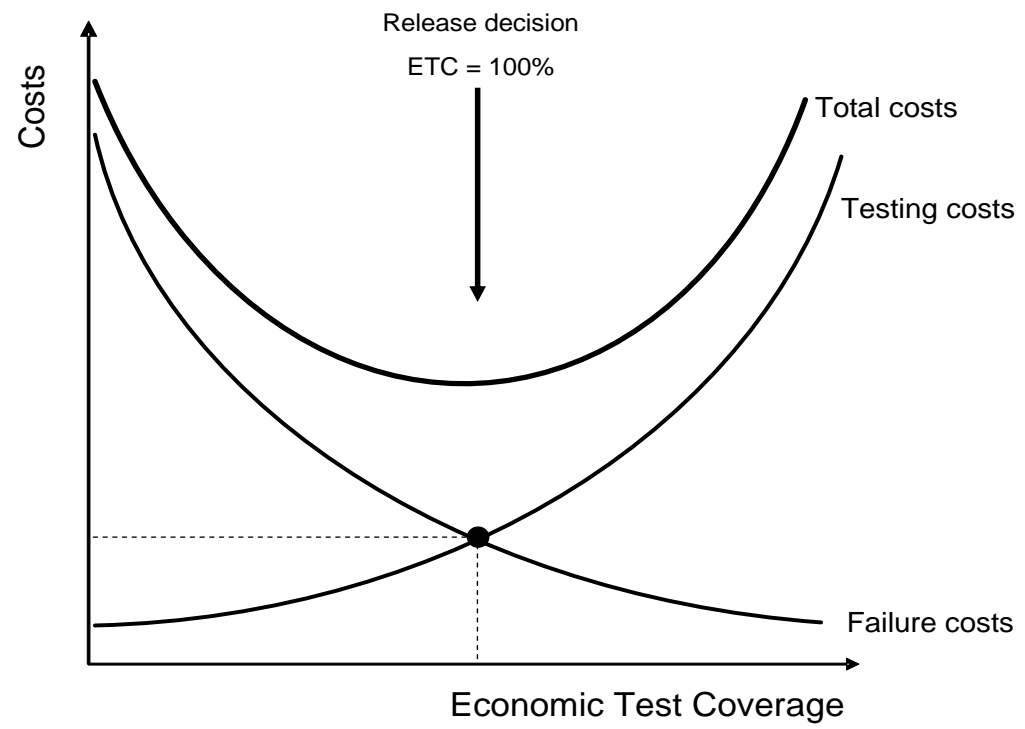

Fig. 4. A new optimization model based on quality costing and risk analysis, enabling optimization of testing on an economic basis. 


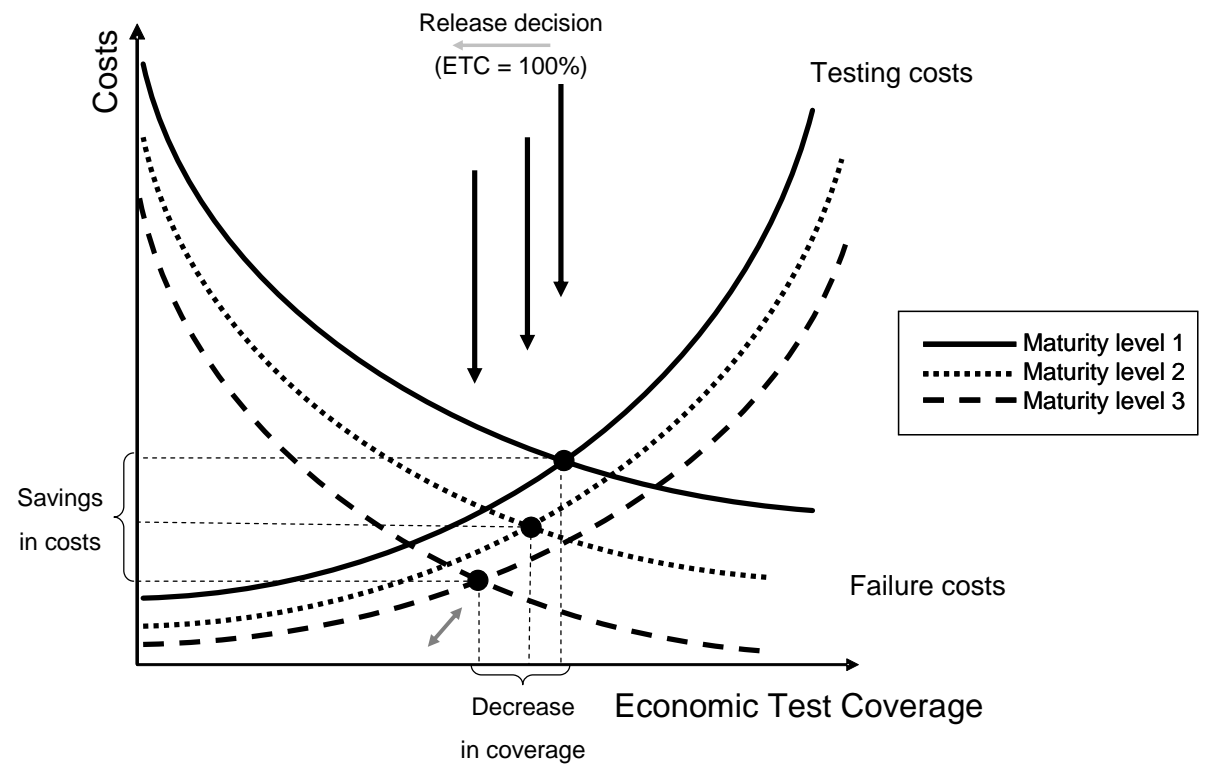

Fig. 5. Theoretical impact of testing maturity on the costs of failures and testing. 


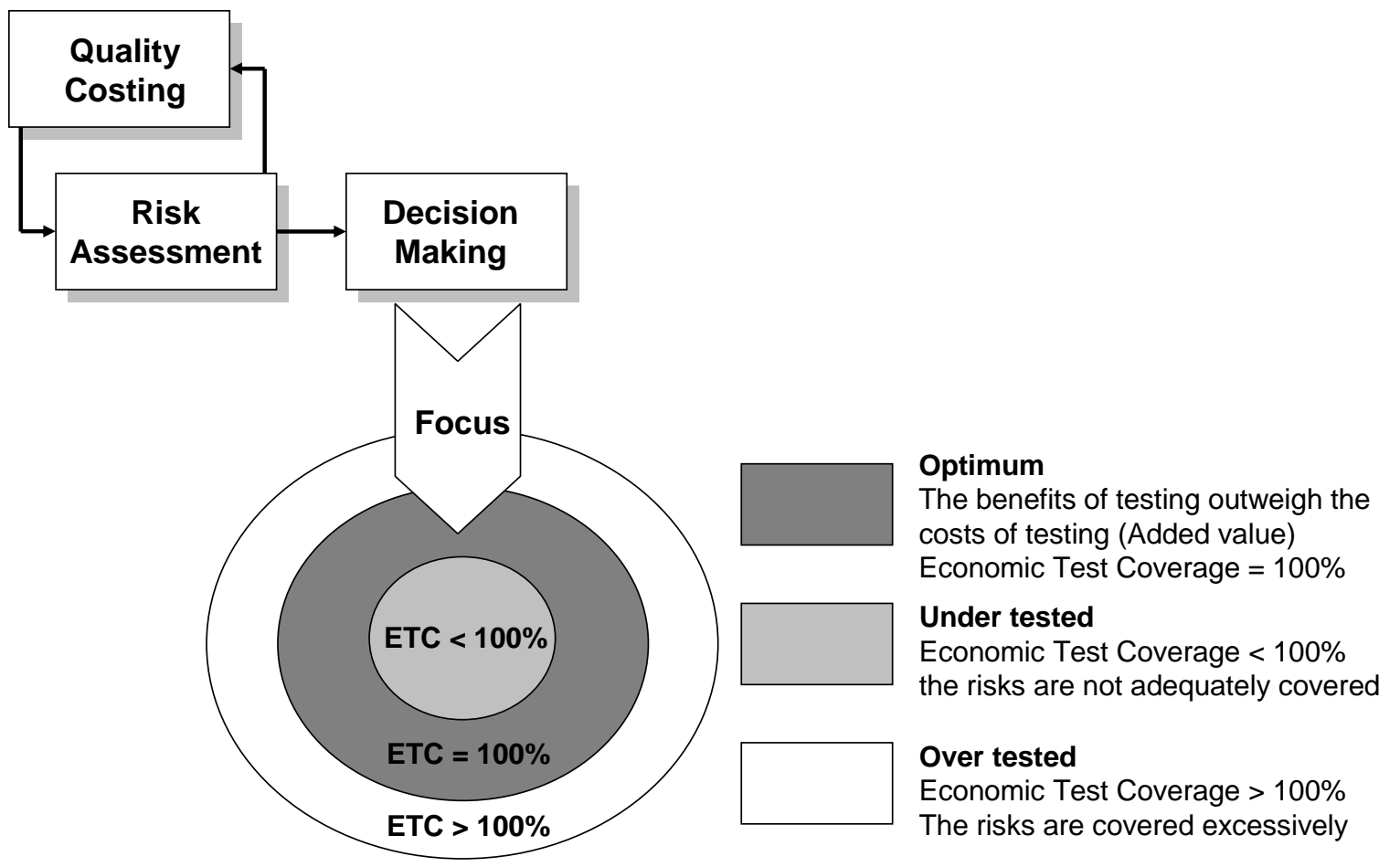

Fig. 6. Focus obtained by quality costing and risk assessment. 


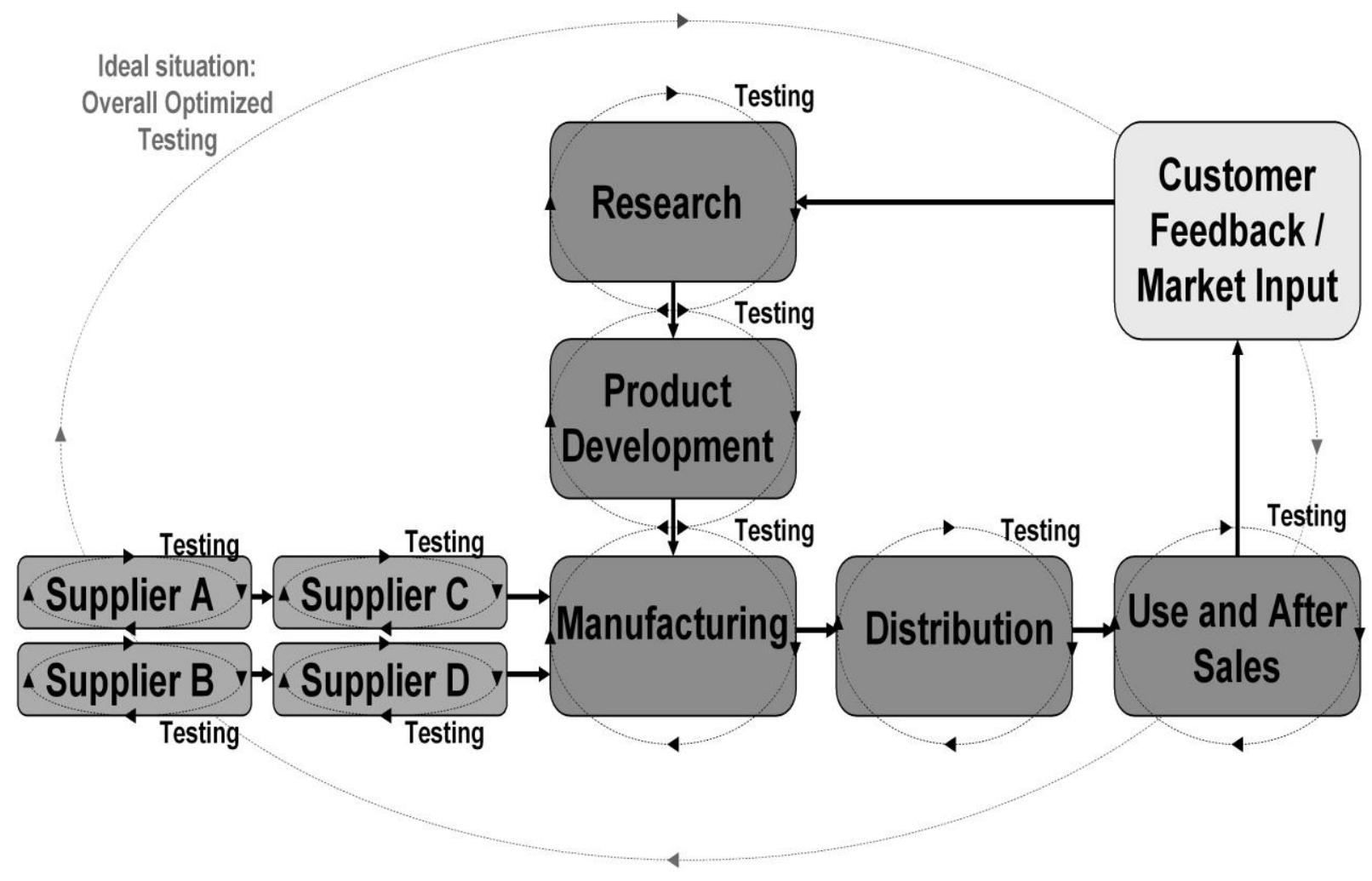

Fig. 7. Product process applied in the study. From sub-optimized testing to total optimization via an integrated testing lifecycle. 


\section{Table 1}

Testing challenge factors identified during the interview study.

\begin{tabular}{ll}
\hline Testing challenge factors & Sub-factors \\
\hline Legacy findings & Legacy designs \\
& Legacy processes \\
& Legacy methods \\
& Dispersed sites \\
& Different backgrounds \\
Organization & Deficient test management \\
& Separate projects \\
& Dependence of individuals \\
& Multi/ Cross-functionality \\
& \\
Culture & Readiness for change vs. resistance for change \\
& Rallying points vs. distinguishing points \\
& Mutual understanding \\
& \\
Know-how & Best practices/ competence \\
& Methods and techniques \\
& Metrics and indicators \\
& Quality and risk level \\
& Suitable data \\
& \\
& Fast technology change \\
& Fast growth --> mature phase \\
& Increasing complexity of the products \\
(technical/ features) & Short-term objectives \\
\hline &
\end{tabular}


Table 2

Testing success factors identified in interview study.

\begin{tabular}{ll}
\hline Testing success factors & Sub-factors \\
\hline Change management & $\begin{array}{l}\text { New mindset } \\
\text { Implementation of changes } \\
\text { Adherence to changes }\end{array}$ \\
Communication and & \\
information management & Objective/ goals \\
& Metric/ indicators \\
& Data gathering \\
& Inputs/ outputs \\
& Reporting \\
& Responsibility \\
& Ownership \\
& Commitment \\
Leadership & Rewarding of achievements \\
& \\
& Common methods, techniques, and automation \\
& Resources \\
Rationalization & Processes \\
& Product architecture (SW/ HW platforms) \\
& Systematic practices \\
& Discrete testing lifecycles \\
Tntegration/ Alignment & Testing policy \\
& Metrics - balanced scorecard \\
& \\
& \\
& \\
& \\
& \\
& \\
& \\
& \\
&
\end{tabular}

